\title{
Estimating the long-term calving flux of Kronebreen, Svalbard, from geodetic elevation changes and mass-balance modelling
}

\author{
Christopher NUTH, ${ }^{1}$ Thomas Vikhamar SCHULER, ${ }^{1}$ Jack KOHLER, ${ }^{2}$ Bas ALTENA, ${ }^{2,3}$ \\ Jon Ove HAGEN ${ }^{1}$ \\ ${ }^{1}$ Department of Geosciences, University of Oslo, Blindern, Oslo, Norway \\ E-mail: christopher.nuth@geo.uio.no \\ ${ }^{2}$ Norwegian Polar Institute, Fram Centre, Tromsø, Norway \\ ${ }^{3}$ Department of Remote Sensing, Delft University of Technology, Delft, The Netherlands
}

\begin{abstract}
This study independently quantifies geodetic elevation change and models surface mass balance to solve the continuity equation. The approach is tested on two dynamically different glaciers, Kongsvegen and Kronebreen in northwest Svalbard, through two time epochs, 1966-1990/95 (I) and 1990/95-2007 (II). On Kongsvegen, a dynamically inactive glacier, the residual term represents an error associated with determining elevation changes and surface mass balance. It is apparent that centerline mass-balance estimates are not representative of the entire glacier, which we relate to center-line accumulation being larger than the elevation bin average. On Kronebreen, a fast-flowing and actively calving glacier, a significant part of the residual is identified with the long-term calving flux. For both glaciers, the cumulative surface mass balance remained close to zero during the first epoch but became increasingly negative in the second epoch. The long-term calving flux of Kronebreen is estimated to be $-0.14 \pm 0.03 \mathrm{~km}^{3}$ w.e. $\mathrm{a}^{-1}$ during epoch I and $-0.20 \pm 0.05 \mathrm{~km}^{3}$ w.e. $\mathrm{a}^{-1}$ in epoch II.
\end{abstract}

\section{INTRODUCTION}

Monitoring changes of glaciers, ice caps and ice sheets is important, both in determining the past and presentday contribution to sea-level fluctuation and to better characterize the present-day changes in relation to climatic fluctuations. Area-wide glacier mass balance can be defined in terms of the total change in water-equivalent volume of a glacier, glacier basin or glacier region. Defined in this way, the total mass balance has two main components, the surface mass balance (assuming englacial and basal components are negligible) and the calving flux. The surface mass balance can be measured in situ, using stakes and snow pits on an annual/seasonal basis and can be modelled on a daily basis from meteorological input data. The calving ice loss of marine-terminating glaciers can be determined by multiplying the depth-averaged velocity of ice in the vicinity of the front by the cross-sectional area, integrated over time. Continuous velocity variations at the front are difficult to obtain, either because of the high risk of losing global navigation satellite system (GNSS) recording instruments, or because remote-sensing techniques have not yet been operationally employed to monitor daily, weekly or monthly velocity averages that can be integrated over a mass-balance year. Therefore, use of this method is restricted to sites and periods with available data, meaning reconstruction of past calving rates is not easy to achieve. However, spaceborne (Burgess and others, 2005; Kääb and others, 2005) and terrestrial (Ahn and Box, 2010) remote sensing are promising techniques for providing such information.

Estimating the volume change of a glacier through measurement of elevation changes is becoming more prevalent with the increasing availability of multitemporal elevation products. Elevation change is important for determining the contribution of glaciers to sea-level change (e.g. Arendt and others, 2002; Abdalati and others, 2004; Zwally and others, 2005; Berthier and others, 2010) and for validating in situ mass-balance measurements (e.g. Krimmel, 1999; Elsberg and others, 2001; Zemp and others, 2010). However, interpreting elevation and volume changes is difficult because they are made up of both climatic and dynamical components. These components are not easily separated, due to the interdependencies between surface mass balance and ice dynamics.

Comparing geodetically measured volume changes with the surface mass balance is commonly limited to landterminating glaciers to validate cumulative mass-balance time series (Andreassen, 1999; Elsberg and others, 2001; Cox and March, 2004; Thibert and others, 2008). Geodetic volume changes have also been used to constrain mass-balance models (Huss and others, 2009). For marine-terminating glaciers, the total mass balance includes both the surface mass balance (including basal and englacial balances) and a calving component. If the surface mass balance can be properly determined, either through extrapolation of in situ point measurements or through modelling, then the residual between the water-equivalent geodetic volume change and the surface mass balance represents the calving component, provided there are no errors.

\section{OBJECTIVES}

The continuity equation has been used to solve for the surface mass balance from remotely sensed elevation changes and horizontal velocities (Gudmundsson and Bauder, 1999; Kääb and Funk, 1999; Hubbard and others, 2000; Kääb, 2000). The goal of this study is to use mass continuity to compare geodetic elevation change with the surface mass balance of two dynamically different glaciers: a glacier in its quiescent phase of a surge cycle with negligible calving and a persistently fast-moving glacier which is actively calving into the sea. Mass-balance measurements are spatially limited to point observations commonly having 


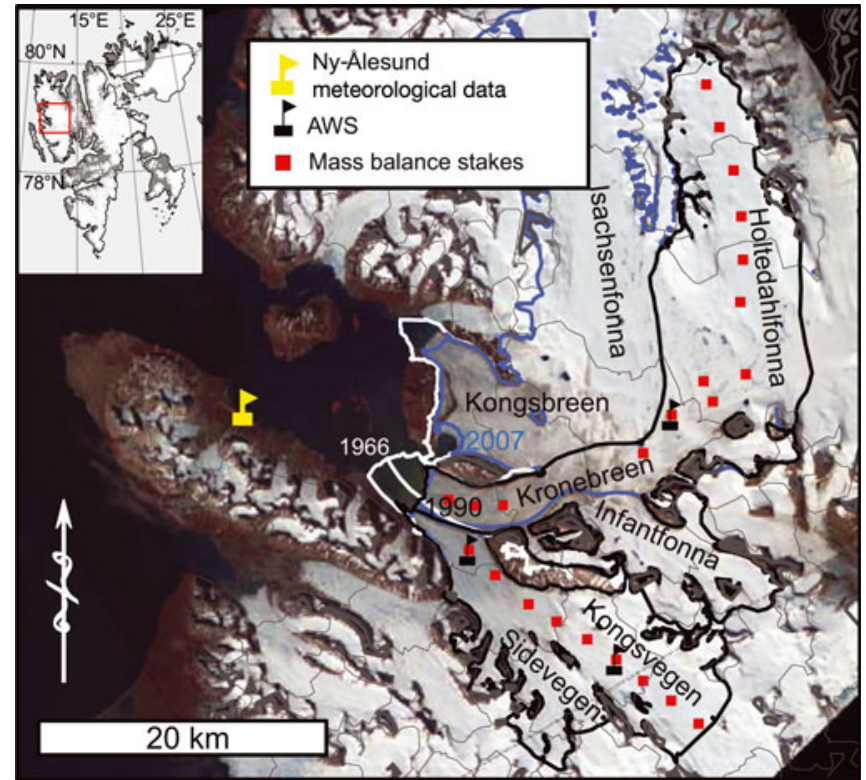

Fig. 1. The location of Kongsvegen and Kronebreen in northwest Svalbard. The location of Ny-Ålesund is denoted by the yellow flag $\sim 15 \mathrm{~km}$ from the glacier front. Kongsvegen and Sidevegen are grouped into one system. Kronebreen consists of Holtedahlfonna and Infantfonna that feed the tongue system. To the north of the Kronebreen system lies Kongsbreen/Isachsenfonna. The border between the two systems is slightly uncertain. Gray lines are $200 \mathrm{~m}$ contours.

a seasonal/annual resolution, whereas elevation changes can be measured over the entire glacier, though typically at lower temporal resolution. We quantify elevation changes by digital elevation model (DEM) differencing of three datasets that cover two time epochs over the past 40 years: epoch I from 1966 to 1990/95 and epoch II from 1990/95 to 2007. In situ mass-balance measurements have been collected at only a few points continuously over the past 10-20 years. Therefore, in situ mass-balance measurements are linked to temperature and precipitation measured since 1969 at a meteorological station in Ny-Ålesund, Svalbard (Fig. 1), using a classical degree-day melt model and a multiple linear regression model for precipitation distribution. Similarly to Huss and others (2009), we do not consider this approach to be a physical representation of the mass balance, but rather a tool for spatial and temporal interpolation/extrapolation, i.e. homogenization of the massbalance time series. Finally, we propose that the difference between the area-integrated elevation change and surface mass balance provides an estimate of the long-term calving flux of a marine-terminating glacier.

\section{STUDY LOCATION}

The two glaciers analyzed in this study, Kongsvegen and Kronebreen, are located in the vicinity of $\mathrm{Ny}$-Ålesund in northwest Svalbard (Fig. 1). Kongsvegen is $\sim 27 \mathrm{~km}$ long, spanning elevations $0-800 \mathrm{~m}$ a.s.l., covering a total area of $\sim 180 \mathrm{~km}^{2}$. Since 1986, the surface mass balance has been measured by the Norwegian Polar Institute (NP) using a series of approximately ten stakes along the center line (Hagen and others, 1999). The glacier has been in a quiescent phase since the last surge in 1948 (Melvold and Hagen, 1998) and the elevation changes are approximately equal to the surface mass balance, due to negligible glacier flow (Melvold and Hagen, 1998; Hagen and others, 1999, 2005). Kongsvegen is therefore an ideal reference case to ensure consistency between the elevation changes and the mass-balance model. For our study, we include Sidevegen as a part of Kongsvegen because these two glaciers share the glacier tongue and the valley.

The Kronebreen glacier system is $\sim 50 \mathrm{~km}$ long with an elevation range $0-1400 \mathrm{~m}$ a.s.l. The $\sim 390 \mathrm{~km}^{2}$ area comprises three named ice masses: the fast-flowing glacier tongue, Kronebreen; the larger upper catchment, Holtedahlfonna; and the smaller cirque contributory glacier, Infantfonna. The divide between the Holtedahlfonna/Kronebreen system and the neighboring Isachsenfonna/Kongsbreen system is slightly uncertain at mid-elevations of the glacier (Fig. 1), where upper and lower elevations are confined by mountains and nunataks. This divide makes the catchment area slightly uncertain in space and time. A subsidiary aim of this study is to present and examine elevation changes of the Kongsbreen/Isachsenfonna system between 1966 and 2007 in relation to the Kronebreen/Holtedahlfonna system. The surface mass-balance program on Holtedahlfonna began in spring 2003; ten stakes were installed along the accessible center line above the crevasse zone (Baumberger, 2008). In 2008 three additional stakes were installed on the lower crevassed area of Kronebreen.

The two glaciers can be considered as dynamically opposite. Kongsvegen has been dynamically inactive since its surge in 1948 (Melvold and Hagen, 1998) and therefore averages low yearly velocities of $\sim 2 \mathrm{~m} \mathrm{a}^{-1}$ at the front with a maximum of $4 \mathrm{ma}^{-1}$ at the equilibrium line (Melvold and Hagen, 1998; Hagen and others, 1999). Kronebreen has never been observed to surge; however, it has been suggested that the late 1800 s glacier-front position was the result of a surge (Liestøl, 1988). Kronebreen exhibits average annual velocities of up to $300-800 \mathrm{~m} \mathrm{a}^{-1}$ at the front (Kääb and others, 2005). The velocity of Kronebreen is consistent between measurements made in 1964 (Voigt, 1966), in 1986 (Lefauconnier and others, 1994a) and around 2000-02 (Kääb and others, 2005). It is therefore one of the most persistent fast-flowing glaciers in Svalbard.

\section{DATA}

\section{Glaciological data}

Surface mass-balance measurements (Østrem and Brugman, 1991) are acquired using $6 \mathrm{~m}$ stakes drilled into the ice/firn where the length of the exposed stake is measured on an annual/seasonal basis. Additional accumulation measurements are acquired across the glacier by snow depth sounding or radar profiling, and the snow density is measured at selected stakes in April/May. In this study, only measurements at stake locations are used for model calibration because they are consistent through the entire time series. Summer measurements are typically acquired in early September. Due to weather-related inaccessibility, not all stakes were measured at the end of summer every year. Therefore, we use the net change in exposed stake heights between two successive April/May measurements minus the previous winter's accumulation to derive the summer balance. In situ mass-balance data are available from 1987 to 2008 for Kongsvegen and from 2003 to 2010 for Kronebreen. Measurement details are given by Melvold and Hagen (1998), Hagen and others (1999) and Baumberger 
Table 1. Data used in this study on Kongsvegen (KNG) and Kronebreen (KRB). The measurements include temperature, $T$, precipitation, $P$, winter, summer and net specific mass balance, $b_{\mathrm{w}}, b_{\mathrm{s}}, b_{\mathrm{n}}$, respectively, sonic sensor depth gauge, $S$, and elevation, $z$. On KNG, there are two operational AWSs for 2007-09. KRB has had one AWS operational since 2007 and a second since 2009. The data originate from the Norwegian Meteorological Institute (met.no), the Norwegian Polar Institute (NP), the University of Oslo (UiO) and from the SPOT5 satellite (Korona and others, 2009)

\begin{tabular}{|c|c|c|c|c|c|}
\hline Year & Parameter & Type/origin & Source & Resolution & Glacier \\
\hline 1969-2009 & $T, P$ & Ny-Ålesund meteorological station & met.no & Daily & KNG/KRB \\
\hline 1987-2008 & $b_{\mathrm{w}}, b_{\mathrm{s}}, b_{\mathrm{n}}$ & Mass-balance stake measurements & NP & Seasonal & KNG \\
\hline 2003-10 & $b_{\mathrm{w}}, b_{\mathrm{s}}, b_{\mathrm{n}}$ & Mass-balance stake measurements & NP/UiO & Seasonal & KRB \\
\hline 2007-09 & $T, S$ & AWS & NP & Hourly & $\mathrm{KNG} / \mathrm{KRB}$ \\
\hline 1966 & $z$ & Aerial photogrammetric DEM + contours & NP & $10 \mathrm{~m}$ & KNG/KRB \\
\hline 1990 & $z$ & Aerial photogrammetric DEM & NP & $10 \mathrm{~m}$ & KRB \\
\hline 1995 & $z$ & Aerial photogrammetric DEM & NP & $10 \mathrm{~m}$ & KNG \\
\hline 1996 & $z$ & GPS profile & UiO & $10 \mathrm{~s}(\sim 40 \mathrm{~m})$ & $\mathrm{KRB}$ \\
\hline 2007 & $z$ & Satellite stereoscopic DEM & SPOT5 & $40 \mathrm{~m}$ & KNG/KRB \\
\hline
\end{tabular}

(2008). Due to the heavily crevassed glacier tongue of Kronebreen, mass-balance measurements were not obtained below 500 ma.s.l. before 2008. Three stakes in this region have been maintained since 2008. However, potential winter ablation has not been successfully measured, due to the disappearance of the stakes between autumn and spring.

\section{Meteorological data}

The Norwegian Meteorological Institute has measured precipitation and temperature in Ny-Ålesund since 1969. In 1974 the weather station was moved to $\sim 34 \mathrm{~m}$ below its original location. Small lapse corrections $\left(0.2^{\circ} \mathrm{C}\right)$ have been shown to have little significance in correlations with mass balance (Lefauconnier and Hagen, 1990). Synoptic weather observations were carried out (three or four times daily), until 1994 when an automatic weather station (AWS) began continuously monitoring at an hourly recording interval (Norwegian Meteorological Institute; http://www.met.no). Before 1994, precipitation measurements were collected manually using a rain gauge; since 1994 the weight of the collected precipitation in the rain gauge has been measured hourly (http://www.met.no). We use daily accumulated precipitation and daily average and maximum temperatures to drive the surface mass-balance model. Average and maximum temperatures are employed to determine whether partial-melting days (i.e. days in which melt occurs but the average temperature is below freezing) influence the model parameter values. In addition, daily average data from AWSs on Kongsvegen and Kronebreen are used to validate distribution of temperature data from Ny-Ålesund (Fig. 1).

\section{Elevation data}

The elevation data consist of DEMs and a GPS profile (Table 1). The 1966, 1990 and 1995 DEMs were generated from vertical aerial imagery acquired in summer, made on a digital photogrammetric workstation (Altena, 2008). The 2007 DEM is a SPOT5-HRS (high-resolution stereo) product (GES07-043-NorthWestSvalbard) obtained through the IPYSPIRIT project (International Polar Year SPOT5 stereoscopic survey of Polar Ice: Reference Images and Topographies; Korona and others, 2009). The DEM is created from satellite stereo imagery of a forward- and backward-looking sensor with a base-to-height ratio of 0.8 (Bouillon and others, 2006). In Svalbard, SPOT5-HRS DEMs are reported to have an elevation accuracy of $3 \mathrm{~m}$ and a precision of $5 \mathrm{~m}$ relative to the Ice, Cloud and land Elevation Satellite (ICESat) (Korona and others, 2009; Nuth and Kääb, 2011).

Since the DEMs from the 1990s do not cover both glaciers fully in a single acquisition, we use a 1995 DEM for Kongsvegen and a 1990 DEM for Kronebreen. The data in 1966 and 1990 were incomplete in some regions, due to low visible contrast (i.e. higher elevations), rendering image matching difficult. The 1966 DEM gaps are filled with the 1966 contour data made previously on an analogue photogrammetric workstation using the same images. The 1990 data on Kronebreen are missing above 700 ma.s.l. (40\% of the glacier area) which we fill using a 1996 differential GNSS elevation profile measured along the approximate center line every $10 \mathrm{~s}(\sim 40 \mathrm{~m})$. The 1996 profile data are elevationally adjusted to 1990 by removing the mean elevation difference in an area of overlap and assuming the glacier slope has not changed. The 1995 DEM of Kongsvegen is not missing any data.

\section{THEORY}

\section{Mass continuity}

Glacier-elevation changes, mass balance and flux of ice in and out of the system are related through the equation of mass continuity. A detailed derivation and discussion of glacier mass continuity is given by Cuffey and Paterson (2010). Here we simplify the discussion and list the assumptions related to combining elevation changes and the surface mass balance. For any volume element of a given material having density $\rho$, mass continuity is written:

$$
\frac{\partial \rho}{\partial t}+\nabla(\rho \vec{u})+\beta=0,
$$

where $\vec{u}$ is a velocity vector and $\beta$ is a production term. Eqn (1) states that any local change in density is balanced by the net flux of material into or out of the considered volume plus any source or sink of mass. Integration from the bed, $h_{\mathrm{b}}$, to the surface, $h_{\mathrm{s}}$, provides the continuity equation for $\mathrm{a}$ vertical column through a glacier:

$$
\frac{\partial}{\partial t} \int_{h_{\mathrm{b}}}^{h_{\mathrm{s}}} \rho \mathrm{d} z=b+\nabla \vec{q}
$$


where

$$
\begin{gathered}
b=b_{\mathrm{s}}+b_{\mathrm{e}}+b_{\mathrm{b},} \\
\nabla \vec{q}=\int_{h_{\mathrm{b}}}^{h_{\mathrm{s}}} \nabla(\rho \vec{u}) \mathrm{d} z .
\end{gathered}
$$

The term on the left-hand side of Eqn (2) represents the change in mass of the given volume and may be approximated through gravity variations (e.g. Wahr and others, 2004; Luthcke and others, 2008) or elevation changes. On the right-hand side, the mass balance, $b$, is the sum of surface $\left(b_{\mathrm{s}}\right)$, englacial $\left(b_{\mathrm{e}}\right)$ and basal $\left(b_{\mathrm{b}}\right)$ components (Eqn (3)). Eqn (4) defines the horizontal flux, $\vec{q}$, as the column average velocity, $\vec{u}$, multiplied by the density, $\rho$, which closely approximates the density of ice in cases where firn is a small proportion of the ice thickness (Cuffey and Paterson, 2010).

To relate the mass change (left-hand side of Eqn (2)) to observed elevation changes, $\partial h / \partial t$, we introduce an effective density, $\rho_{\text {eff, }}$ to express the temporal and vertical changes of the column density:

$$
\frac{\partial}{\partial t} \int_{h_{\mathrm{b}}}^{h_{\mathrm{s}}} \rho \mathrm{d} z \approx \frac{\partial h}{\partial t} \rho_{\mathrm{eff}} .
$$

We continue in water-equivalent units because this is the common measuring practice for glacier mass balance, $b$. We now assume that englacial and basal mass balances are negligible $\left(b_{\mathrm{e}} \ll b_{\mathrm{s}}\right.$ and $\left.b_{\mathrm{b}} \ll b_{\mathrm{s}}\right)$ and that the flux divergence, $\nabla \vec{q}$, represents mass change of incompressible ice. The continuity expression can then be reduced to

$$
\frac{\partial h}{\partial t} \cdot \kappa=\left(b_{\mathrm{s}}+\nabla \vec{q}\right) \cdot \rho_{\mathrm{w}}^{-1}
$$

where $\rho_{\mathrm{w}}$ is the density of water and $\kappa$ is a conversion factor from height differences to water-equivalent changes:

$$
\kappa=\frac{\rho_{\mathrm{eff}}}{\rho_{\mathrm{w}}} .
$$

If $\partial h / \partial t$ is observed over a significantly long time period, $\kappa$ can be approximated by the density ratio of ice to water (0.9) below the equilibrium-line altitude (ELA). This is because small changes in the less dense snow have little impact on the column average density and thus all changes will be of incompressible glacier ice. In the firn area, changes in the proportion of firn in the ice column can alter $\kappa$, due to the compressibility of firn. It is often assumed that firn thickness and density are constant through time (Sorge's law; Bader, 1954), in which case $\kappa=0.9$.

Solving mass continuity over the entire glacier system requires integration of Eqn (6) over the glacier surface area, A:

$$
\iint_{A} \frac{\partial h}{\partial t} \cdot \kappa \cdot \mathrm{d} x \mathrm{~d} y=\frac{\partial V}{\partial t}=B+\iint_{A} \nabla \overrightarrow{\hat{q}} \mathrm{~d} x \mathrm{~d} y,
$$

with all terms in water equivalent. Eqn (8) relates the volume change, $\partial V / \partial t$, to the water-equivalent flux divergence, $\nabla \overrightarrow{\hat{q}}$, and the glacier-wide mass balance, $B$. Applying the divergence theorem to the last term in Eqn (8) results in the relationship between the glacier-wide integrated flux and the water-equivalent flux through a boundary, $R$

$$
\iint_{A} \nabla \overrightarrow{\hat{q}} \mathrm{~d} x \mathrm{~d} y=\oint_{R}(\overrightarrow{\hat{q}} \vec{n}) \mathrm{d} r
$$

and substitution into Eqn (8) results in

$$
\frac{\partial V}{\partial t}=B+\oint_{R}(\overrightarrow{\hat{q}} \vec{n}) \mathrm{d} r,
$$

where $\vec{n}$ is the normal vector to the closed boundary, $R$. The second term on the right-hand side may represent the influx of ice by avalanching or the loss through calving and potential submarine melting on the calving face.

Using Eqn (10), we consider two solutions: noncalving and calving glaciers. Often for non-calving glaciers, $\oint_{R}(\vec{q} \vec{n}) \mathrm{d} r$ is assumed equal to zero, resulting in

$$
\frac{\partial V}{\partial t}=B
$$

This has formed the basis of many comparison studies aimed at detecting systematic errors in the cumulative, glacier-wide in situ surface mass-balance values by using geodetically measured volume changes (e.g. Krimmel, 1999; Elsberg and others, 2001; Cox and March, 2004; Thibert and others, 2008; Zemp and others, 2010). For a calving glacier, $\oint_{R}(\vec{q} \vec{n}) \mathrm{d} r$ is equal to the flux, $Q$, through the boundary, $R$, of the glacier:

$$
\frac{\partial V}{\partial t}=B+Q
$$

Practically, solving mass continuity of an entire glacier system requires definition of the boundary geometry. For simplicity, or due to lack of updated maps, this geometry may be held constant. For example, Elsberg and others (2001) introduce the concepts of a 'reference' and 'conventional' surface for mass-balance integration and suggest a transformation between them. The 'reference' surface is a constant map (elevation and extent) and is considered to be more climate-related, as it ignores the effects of surface change on the mass balance. The 'conventional' massbalance surface is the actual mass change of the glacier relevant for hydrological and sea-level change studies. In the following, we consider mainly the change in glacier extent through time due to the stronger influence on mean mass balance than that of a changing surface elevation (Paul, 2010). Nevertheless, changing surface elevations are roughly compensated for in the surface mass-balance model through our use of an average elevation of the two DEMs within an epoch. Eqn (12) can be modified to handle the volume of retreat/advance separately:

$$
\frac{\partial V_{\mathrm{r} / \mathrm{a}}}{\partial t}=B_{\mathrm{r} / \mathrm{a}}+Q_{\mathrm{r} / \mathrm{a}}
$$

where

$$
Q_{\mathrm{r} / \mathrm{a}}=Q^{\prime}-Q \text {. }
$$

Derived in this way, $\partial V / \partial t$ and $B$ of Eqns (11) and (12) can be solved using a 'reference' surface, defined as the smallest glacier area. $Q$ is then the ice flux through the crosssectional area (flux gate) defined by the glacier front at the time of smallest glacier area (i.e. the most recent area in cases of retreat). In Eqn (13), $\partial V_{\mathrm{r} / \mathrm{a}} / \partial t$, and $B_{\mathrm{r} / \mathrm{a}}$ are the volume change and mass balance of the receding ( $r$ ) or advancing (a) area. Quantifying $\partial V_{\mathrm{r} / \mathrm{a}} / \partial t$ is not a problem, provided we have knowledge of the basal elevation or depth below sea level in the retreat or advance area. $B_{\mathrm{r} / \mathrm{a}}$ can be solved by assuming a linear retreat of the front. $Q_{r / a}$ is defined as the retreat/advance flux and is the difference between the net flux into or out of the glacier, $Q^{\prime}$, and the flux out of the gate defined by the front of the smallest area, $Q$. Hence, $Q_{\mathrm{a}}>0$ and $Q_{r}<0$. 
Table 2. Precision and accuracy of the geodetic datasets. The shift vector solutions for the co-registration $(\mathrm{d} x, \mathrm{~d} y$ and $\mathrm{d} z)$ between the elevation products $(A=1966 ; B=1990 ; C=1995$; $D=2007)$ are shown. The standard deviation of stable terrain after co-registration represents the stochastic error (precision) associated with an individual elevation-change pixel or point. The triangulated residuals in the lower section of the table represent the systematic coherence (accuracy) between the three or four data products. Most important is the residual about the $z$-axis which is the systematic vertical bias remaining. All units are in meters

\begin{tabular}{lrrrr}
\hline Vector notation & $\mathrm{d} x$ & $\mathrm{~d} y$ & $\mathrm{~d} z$ & $\sigma$ \\
$\overrightarrow{\overrightarrow{A B}}$ & 0.00 & 0.00 & -0.73 & 8.12 \\
$\overrightarrow{A C}$ & 0.00 & 0.00 & 2.08 & 5.42 \\
$\overrightarrow{A D}$ & 27.52 & -41.14 & -2.40 & 10.22 \\
$\overrightarrow{B C}$ & 0.00 & 0.00 & 2.50 & 4.40 \\
$\overrightarrow{B D}$ & 26.95 & -42.50 & -3.20 & 6.33 \\
$\overrightarrow{C D}$ & 28.76 & -41.88 & -4.85 & 7.50 \\
$\overrightarrow{A B}+\overrightarrow{B D}-\overrightarrow{A D}$ & -0.56 & -1.37 & -1.53 & - \\
$\overrightarrow{A C}+\overrightarrow{C D}-\overrightarrow{A D}$ & 1.24 & -0.74 & -0.37 & - \\
$\overrightarrow{A B}+\overrightarrow{B C}-\overrightarrow{A C}$ & 0.00 & 0.00 & -0.31 & - \\
$\overrightarrow{B C}+\overrightarrow{C D}-\overrightarrow{B D}$ & 1.81 & 0.63 & 0.85 & - \\
$\overrightarrow{A B}+\overrightarrow{B C}+\overrightarrow{C D}-\overrightarrow{A D}$ & 1.24 & -0.74 & -0.68 & - \\
& & & & -
\end{tabular}

\section{METHODS}

\section{Elevation and volume changes}

Elevation changes are calculated for two time epochs using the data listed in Table 1: 1966-1995-2007 for Kongsvegen and 1966-1990-2007 for Kronebreen. The 1966, 1990 and 1995 DEMs are resampled to $40 \mathrm{~m}$ (SPOT5-HRS DEM resolution) using a $4 \times 4$ window average block filter on the original $10 \mathrm{~m}$ products. DEM pairs are co-registered using the sinusoidal dependency between the vertical differences over stable terrain with aspect (Nuth and Kääb, 2011). The most distinct shift between the products occurs in the 2007 SPOT5-HRS DEM because the 1966 and 1990 data are obtained using roughly the same ground-control points. The triangulation of shift vectors between three DEMs for Kongsvegen and Kronebreen shows a horizontal and vertical coherency of $<2 \mathrm{~m}$ (Table 2 ). This vertical residual represents the accuracy after removal of vertical systematic biases, and becomes noticeable when analyzing the mean glacier elevation change. The stochastic errors (precision) of the datasets are generally better than $10 \mathrm{~m}$ ( $\sigma$ in Table 2$)$. No elevation-dependent biases are detected.

Estimating volume changes from elevation changes can be accomplished using two methods, typically depending on whether the data available are center-line profiles (Arendt and others, 2002) or full-range DEMs (Berthier and others, 2010). The volume change derived from differential DEMs is the summation of the elevation-change pixels over the glacier surface multiplied by the pixel area ('grid' method). If only center-line data are available, a 'hypsometric' approach can be employed, assuming elevation changes across an elevation bin are normally distributed (Berthier and others, 2004). In this method, volume change is derived by summation of the product between elevation change as a function of elevation (average or centerline assumed average) and the glacier hypsometry (areaaltitude distribution). Converting volume change to mass change requires knowledge of the effective density, typically assuming all elevation changes consist of changes in ice thickness $(\kappa=0.9)$.

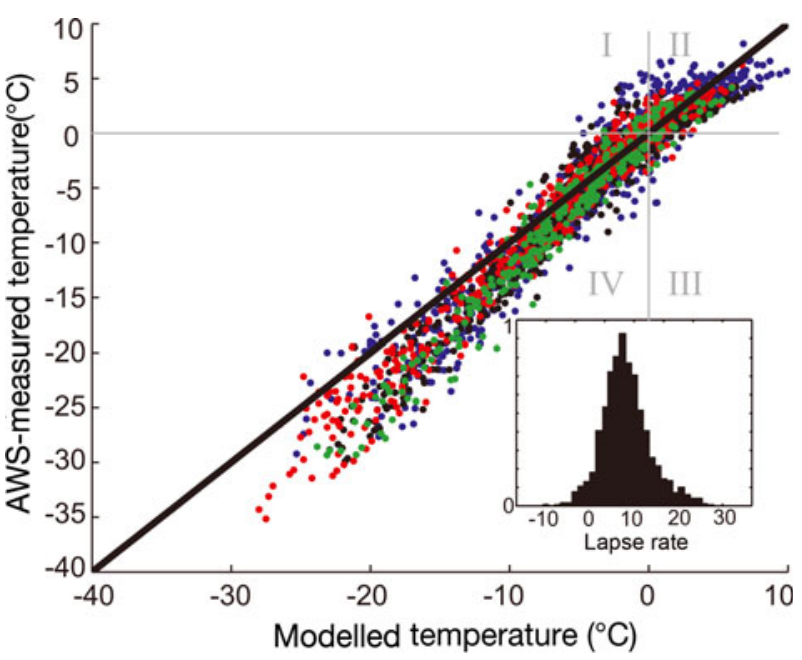

Fig. 2. Measured and modelled temperatures at each AWS from NyAllesund using the environmental lapse rate of $6.6 \mathrm{~K} \mathrm{~km}^{-1}$. The inset shows the histogram of calculated lapse rates $\left(\mathrm{K} \mathrm{km}^{-1}\right)$ at all the stations. The data from AWSs at Kongsvegen stakes 1 (150 ma.s.l.) and 6 (500 ma.s.l.) are shown in blue and black, respectively, and those on Kronebreen stakes 2 (550 ma.s.l.) and 4.5 (650 ma.s.l.) are shown in red and green, respectively. The roman numerals represent the error type quadrants relevant for model melt where the $0^{\circ} \mathrm{C}$ threshold distinguishes between melt and no melt. In Type I errors, melt is observed but not modelled (underestimation), whereas Type III errors result in days that melt is modelled but not observed (overestimation). Type II and IV errors are when both measured and modelled temperatures are above and below zero, respectively.

\section{Surface mass-balance (SMB) model}

The SMB model is driven at a daily time-step using meteorological data from Ny-Ålesund over the period 19692007. The model is calibrated for each glacier individually using the entire time series of available point mass balances (Table 1) in order to derive model parameters individually for each glacier. This decision is based upon a priori knowledge that Kongsvegen receives, on average, slightly more accumulation at its highest elevation $(800 \mathrm{~m})$ than Kronebreen at $1400 \mathrm{~m}$ and due to the large superimposed ice zone on Kongsvegen (König and others, 2002; Langley and others, 2007; Brandt and others, 2008) and the possible lack of one on Kronebreen (Baumberger, 2008).

\section{Distributing temperature}

Temperature is distributed over the glacier by applying a lapse rate to the mean and maximum daily temperatures measured in $\mathrm{Ny}$-Ålesund. Lapse rates generally vary depending upon the moisture content of the atmosphere, with average values $\sim 6.6 \mathrm{~K} \mathrm{~km}^{-1}$, referred to as the environmental lapse rate. Lapse rates are calculated using data from the $\mathrm{Ny}$-Ålesund station and the four AWSs that are available for the period 2007-09. The calculated lapse rates are slightly skewed, with an average of $8.5 \mathrm{~K} \mathrm{~km}^{-1}$ and a standard deviation of $4 \mathrm{~K} \mathrm{~km}^{-1}$ (Fig. 2, inset). The skewed distribution is a result of the cold drier conditions in winter, when lapse rates are closer to $10 \mathrm{~K} \mathrm{~km}^{-1}$. Removal of all temperatures below $-10^{\circ} \mathrm{C}$ results in normally distributed lapse rates with a mean equal to the environmental rate of $6.6 \mathrm{~K} \mathrm{~km}^{-1}$, which is used in this study for distributing temperature. For melt modelling, a lapse rate higher than the environmental lapse rate would result in more Type I errors than Type III (see Fig. 2 


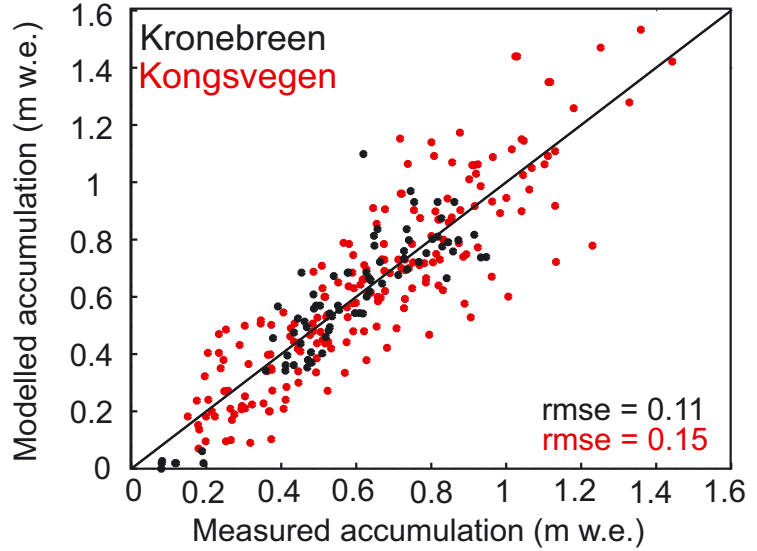

Fig. 3. Measured vs modelled accumulation at the stake measurements of Kongsvegen and Kronebreen. The specific point error is $\sim 0.15$ m w.e. (rmse).

and caption for a description of error types), leading to an overestimation of melt.

\section{Distributing precipitation}

Accumulation in the region is highly dependent upon elevation and related to the sum of precipitation from October to May at the Ny-Ålesund meteorological station (Lefauconnier and others, 1999). The Ny-Ålesund precipitation time series is spatially and temporally distributed over the glaciers using a stepwise multiple regression between the winter balance measurements and elevation, $z$, sum of precipitation, $P_{\text {sum, }}$ mean winter temperature, distance to $\mathrm{Ny}$-Ålesund and geographic location. The final regression model containing only significant parameters is

$$
A(x, y, a)=c_{1} \cdot z(x, y)+c_{2} \cdot z(x, y) \cdot P_{\text {sum }}(w / s),
$$

where $A(x, y, a)$ is a rasterized seasonal accumulation map (m) (see Schuler and others, 2007; Taurisano and others, 2007) describing the spatial distribution ( $x$ and $y$ are Universal Transverse Mercator (UTM) coordinates) for each mass-balance season, based upon the sum of precipitation, $P_{\text {sum, }}$ from October to May for the winter season, $w$, and from June to September for the summer, s. The regression coefficients, $\mathrm{c}_{1}$ (dimensionless) and $\mathrm{c}_{2}\left(\mathrm{~m}^{-1}\right)$, are obtained independently for each glacier through least-squares minimization of all available stake measurements. The rootmean-square error (rmse) between the stake measurements and the model is 0.11 and $0.15 \mathrm{mw}$.e. for Kronebreen and Kongsvegen, respectively (Fig. 3). We assume that lateral variability of accumulation at a particular elevation interval is normally distributed around the center-line stake measurements. An independent regression coefficient for $P_{\text {sum }}$ became insignificant after inclusion of the interaction term, $z \cdot P_{\text {sum, }}$ because a relatively low-precipitation year at sea level (e.g. Ny-Ålesund) does not necessarily result in low accumulation at higher elevations on the glacier; thus the interannual variability of accumulation is larger at sea level than at higher elevations.

Implementation of the regression model is obtained by first determining the annual accumulation map $(A(x, y, a)$ in Eqn (15)) that contains daily time-step $t$. This accumulation map is then normalized using the Ny-Ålesund record of daily precipitation, $P(t)$, divided by the sum of precipitation, $P_{\text {sum, }}$, in the respective winter ( $w$, October-May) or summer (s,
June-September) season:

$$
A(x, y, t)=A(x, y, a) \cdot \frac{P(t)}{P_{\text {sum }}(\mathrm{w} / \mathrm{s})},
$$

where $A(x, y, t)$ is the daily spatially distributed accumulation field. This approach assumes that the summer precipitation distribution is similar to the previous winter. If the mean temperature at pixel $i$ is below the snow temperature threshold, $T_{\mathrm{s}}$, then snow is distributed. We choose $T_{\mathrm{S}}$ to be $+1.5^{\circ} \mathrm{C}$, as it has been observed that mixed rain/snow occurs up to at least $2^{\circ} \mathrm{C}$ above the freezing point (US Army Corps of Engineers, 1956).

\section{Melt model}

The high correlations between temperature and several of the energy-balance components (Braithwaite, 1981; Ohmura, 2001; Sicart and others, 2008) have allowed melt to be successfully modelled using temperature alone (Hock, 2003). We apply a simple melt model, the classical degreeday method, as it is only dependent upon temperature, for which observations in Ny-Ålesund are available. Melt, $M$, is calculated at each glacier pixel, $(x, y)$, for each day, $t$, that temperature, $T$, is above the melt threshold, $T_{\mathrm{m}}$, using separate positive degree-day factors (DDFs) for snow and ice:

$M(x, y, t)= \begin{cases}\operatorname{DDF}(\text { snow } / \text { ice })\left(T(x, y, t)-T_{\mathrm{m}}\right) ; & T>T_{\mathrm{m}} \\ 0 ; & T \leq T_{\mathrm{m}} .\end{cases}$

DDFs are expected to be different for snow- and ice-covered surfaces due to the varying albedo (Braithwaite, 1995), so the DDF for ice is assumed higher than that for snow. We determine DDFs by minimizing the rmse of the residuals between the model and the specific summer net balance stake measurements, independently for each glacier.

The temperature at each gridpoint, $(x, y)$, is estimated by distributing temperature in Ny-Ålesund using the environmental lapse rate and the DEM. The diurnal maximum temperature, $T_{\max }$, is used rather than the diurnal average temperature, $T_{\text {mean, }}$ because there are many days in early spring and autumn when temperatures above freezing occur (thus melting) but $T_{\text {mean }}$ is below freezing due to cold nights. The missed melting on days when $T_{\text {mean }}<0$, is compensated for by an increased DDF for snow in relation to that for ice in order to melt the snowpack faster (Van den Broeke and others, 2010). In this study, using $T_{\text {mean }}$ also resulted in $\mathrm{DDF}_{\text {snow }}>\mathrm{DDF}_{\text {ice. }}$ Van den Broeke and others (2010) solve this by decreasing $T_{\mathrm{m}}$. We choose to use $T_{\max }$ with $T_{\mathrm{m}}=0$, which is equivalent to using $T_{\text {mean }}$ and setting $T_{\mathrm{m}}$ equal to $-2^{\circ} \mathrm{C}$ (Fig. 4).

\section{RESULTS}

\section{Geometry changes}

By 2007, Kongsvegen and Kronebreen had lost about 5\% and $1 \%$ of their 1966 area, respectively. The majority of area loss occurred in the 1966-1990/95 epoch and the front position has remained relatively stable since 1990/95. Within the time frame of this study, the medial moraine dividing the two glaciers has migrated, reflecting the mass flux variations between the two glaciers (Kääb and others, 2005). In 1966 Kongsvegen occupied $\sim 50 \%$ of the calving front, whereas in 2007 the glacier rested on land. The elevation changes for the different epochs are shown in Figure 5. The retreat of the glacier front is apparent (Fig. $5 f$ 
and g) as increasingly negative elevation changes between 0 and $150 \mathrm{~m}$ a.s.l. Retreat from 1990 to 2007 is negligible.

On Kongsvegen, the elevation change rate remained relatively stable between the two time epochs (Fig. 5f). Above $550 \mathrm{~m}$ a.s.l., the glacier surface elevation increases, greatest along the center line (up to $+1 \mathrm{~m} \mathrm{a}^{-1}$ ) compared with the average of the elevation interval. This is especially true for epoch I, less so during epoch II, which is in agreement with the decreased thickening observed by Hagen and others (2005). Also, elevation increases occur lower ( $400 \mathrm{~m})$ on Sidevegen than on Kongsvegen $(\sim 500 \mathrm{~m})$, visible as the cloud of gray dots between 300 and 500 ma.s.l. in Figure $5 f$ that deviate from the Kongsvegen center line.

On Kronebreen, $\partial h / \partial t$ of the glacier tongue for the full period (1966-2007) is similar to Kongsvegen as well as Kongsbreen (Fig. 1, cf. Fig. 5a). During epoch I, frontal thinning rates were similarly intense at Kongsvegen and Kronebreen, but slightly less pronounced on Kongsbreen (Fig. 5b). Conversely, during epoch II, the largest elevationchange rates occur on Kongsvegen and Kongsbreen (about -2 to $-3 \mathrm{ma}^{-1}$ ) while Kronebreen shows an elevation change of about $-1 \mathrm{~m} \mathrm{a}^{-1}$ over the entire surface (Fig. $5 \mathrm{c}$ ). Kronebreen's frontal thinning rate in epoch II is only 33-66\% of that observed in epoch I. The spatial and temporal $\partial h / \partial t$ variation between the glaciers and epochs suggests variation in ice dynamics.

Due to the lack of data in the upper area of Kronebreen (mainly in the 1990 DEM), the center-line differential GPS (dGPS) profile from 1996 is compared with both the 1966 and 2007 DEMs (Fig. 5b, c and g). Before differencing, the mean difference between the dGPS and overlapping 1990 DEM is estimated and removed from the 1996 heights to provide an estimated 1990 surface. This assumes that the relative geometry remained constant between 1990 and 1996 and all elevation differences are uniform within this period. This seems to be the case, at least for the longer 19662007 differences which remain relatively constant from about -0.75 to $+0.25 \mathrm{~m} \mathrm{a}^{-1}$ above $700 \mathrm{~m}$ a.s.l. However, from 1966 to 1990, the elevation-change rates above $700 \mathrm{~m}$ a.s.l. were closer to zero while after 1990 they were closer to $-1 \mathrm{~m} \mathrm{a}^{-1}$. Above $400 \mathrm{~m}$ a.s.l., the elevation change rate is less negative during epoch I than during epoch II, while below $400 \mathrm{~m}$ a.s.I. the elevation change rate is less negative during epoch II than in epoch I. Compared with Kongsvegen, there is less lateral variability of elevation changes at the highest elevation bins, suggesting that center-line values represent those for the entire elevation bin at Kronebreen but not Kongsvegen.

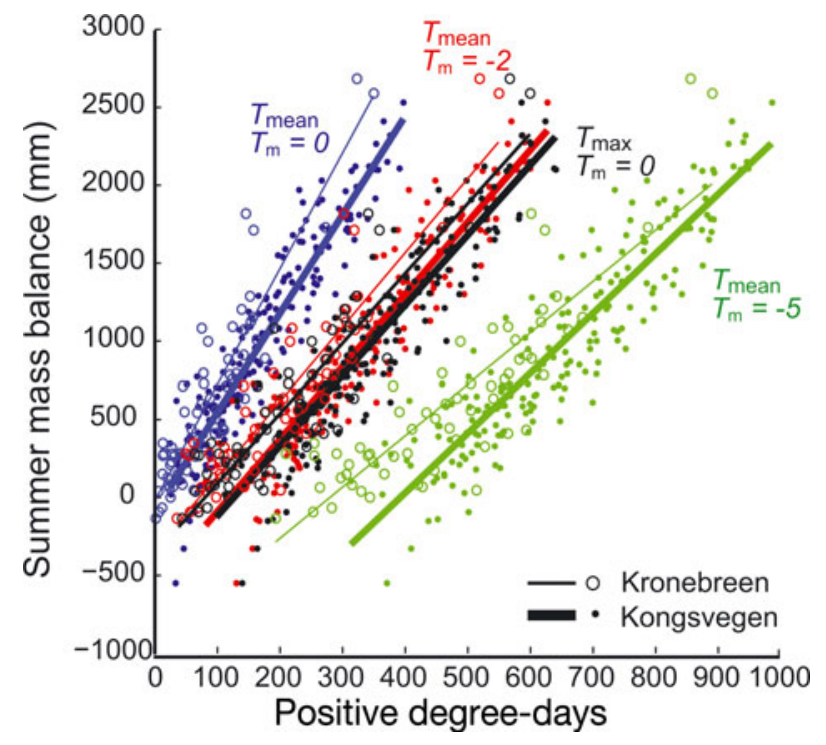

Fig. 4. Sum of positive degree-days (PDD) vs the summer ablation (plotted with melt as positive) for each stake and year for Kongsvegen and Kronebreen. Four scenarios for calculating PDDs are shown: three using the mean diurnal temperature, $T_{\text {mean, }}$ with $T_{\mathrm{m}}=0,-2$ and $-5^{\circ} \mathrm{C}$ and one using the maximum diurnal temperature, $T_{\max }$, and $T_{\mathrm{m}}=0^{\circ} \mathrm{C}$.

\section{Surface mass-balance model}

Table 3 shows calibrated DDF values and the rmse between measured and modelled SMB from various periods. On Kongsvegen, the 21 year stake record results in DDFs of 3.0 and $3.5 \mathrm{~mm} \mathrm{~K}^{-1} \mathrm{a}^{-1}$ for snow and ice, respectively. On Kronebreen, DDFs for snow and ice are 3.1 and $4.7 \mathrm{~mm} \mathrm{~K}^{-1} \mathrm{a}^{-1}$, respectively. Using these parameter sets, the model is applied to the time series of meteorological data. Figure 6 shows the mass balance measured at each stake vs the corresponding modelled value for all years (individual years are shown in the Appendix, Fig. 9). On Konsgvegen, the rmse of winter, summer and net stake mass balances are $0.24,0.26$ and $0.35 \mathrm{~m} \mathrm{a}^{-1}$, respectively (Table 3 ). On Kronebreen, the corresponding rmse values are $0.18,0.29$ and $0.33 \mathrm{~m} \mathrm{a}^{-1}$, respectively.

Figure 7 shows the modelled cumulative net mass balance since 1969. In general, the SMB of Kongsvegen remained close to zero until becoming more negative in the late 1990s. Kronebreen was slightly positive during epoch I, but also turned more negative in epoch II. Superimposed on the figure are the geodetic balances estimated for the entire period

Table 3. Calibrated parameter sets for the precipitation distribution model ( $c_{1}$ and $c_{2}$ of Eqn (15)) and degree-day factors (DDF) of the melt model (Eqn (17)). Three periods are shown on Kongsvegen because the time series is long enough to analyze different parameter sets for the two epochs. The rmse between the specific mass-balance measurements and the model for all years is also given

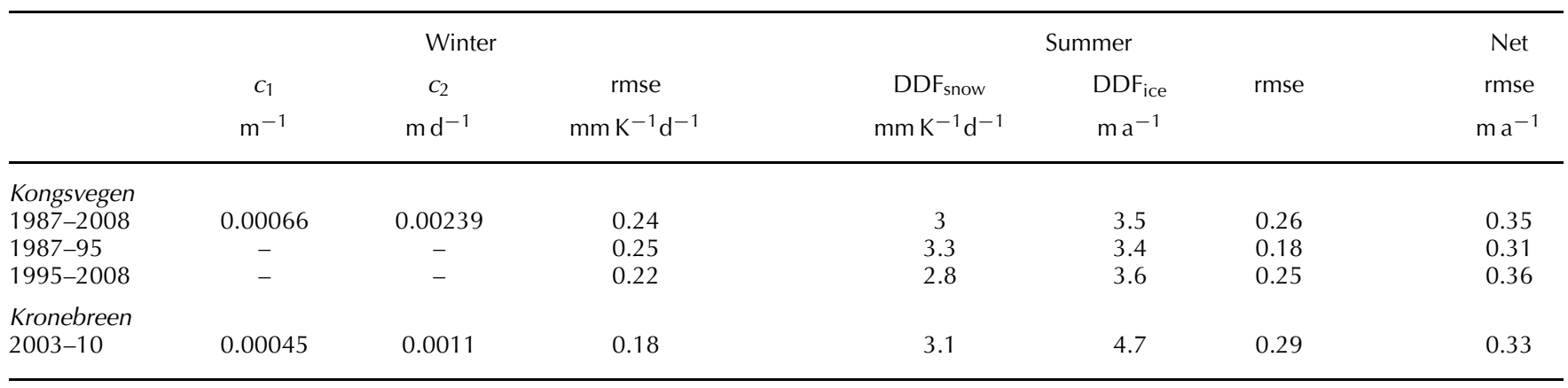




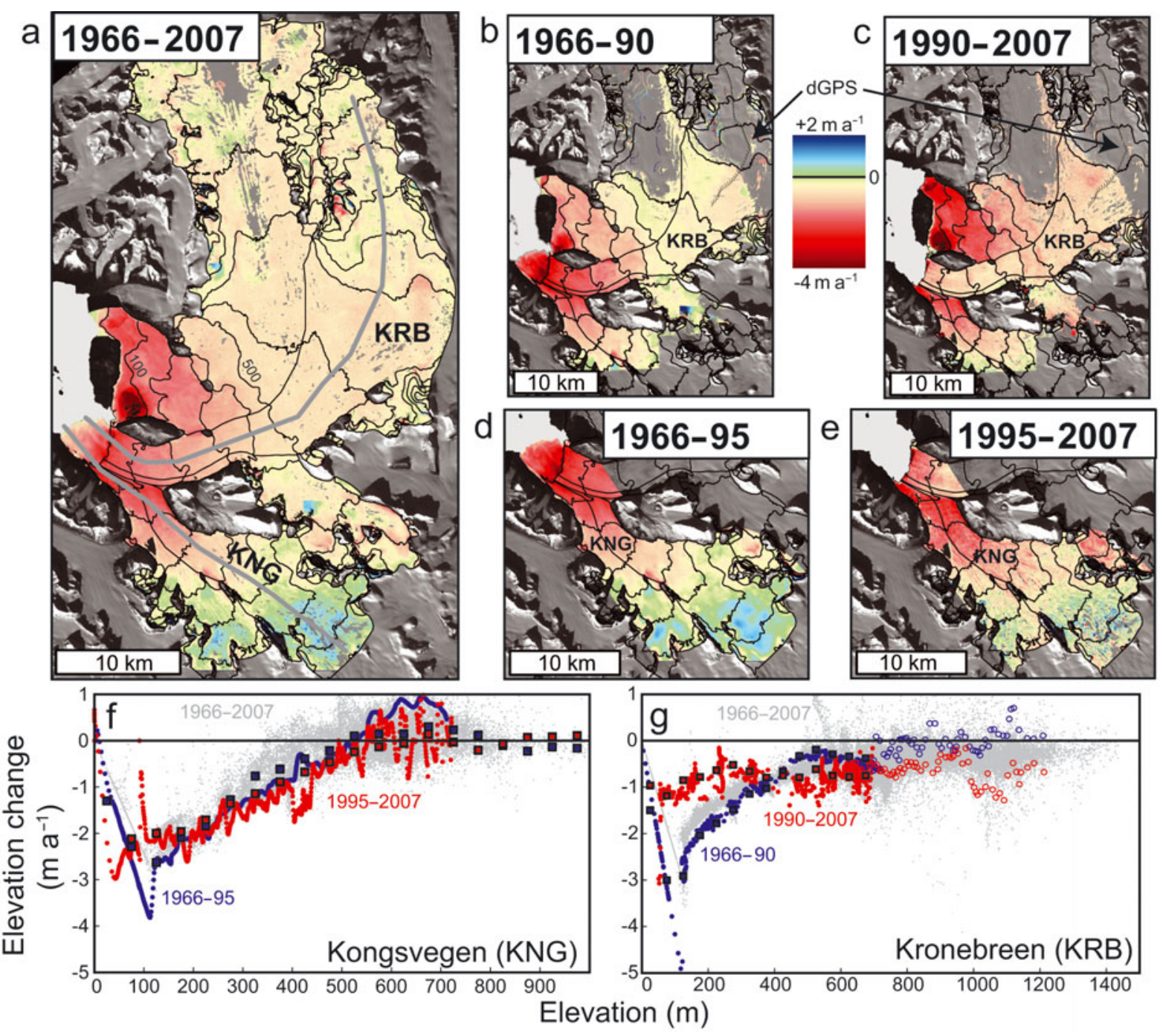

Fig. 5. Elevation-change rates on Kongsvegen, Kronebreen and Kongsbreen for (a) the entire time series, 1966-2007, (b, d) epoch I (19661990/95) and (c, e) epoch II (1990/95-2007). Elevation losses over the marine retreat area do not include ice below sea level. The gray solid lines in (a) represent the center lines of both glaciers. (f, g) Elevation-change rates as a function of elevation for each glacier. In gray are all $\partial h / \partial t$ pixels from the entire time series (1966-2007) where full spatial distribution is possible. $\partial h / \partial t$ for epochs I and II are shown for the center line (solid circles), GPS (unfilled circles) and $50 \mathrm{~m}$ elevation interval averages (unfilled squares).

and in epochs I (1966-1990/95) and II (1990/95-2007). The difference between the entire geodetic time series (19662007) and the sum of epoch I and epoch II is the unremoved systematic bias shown in the residual triangulation of Table 2.

On Kongsvegen, the area-averaged elevation change, estimated by integrating $\partial h / \partial t$ over the glacier area, is $\sim 3 \mathrm{~m}$ more negative than SMB (Fig. 7). The underestimation of the SMB model is an extrapolation failure, due to the predominance of $z$ for distributing $T$ and $P$, so horizontal variability is not accounted for. Spatial variability is seen in the elevation-difference maps (Fig. 5a and f) in which the center-line $\partial h / \partial t$ shows much more thickening than the average per elevation bin above the ELA. Integrating the center-line $\partial h / \partial t$ using the 'hypsometric' approach results in an area-averaged elevation change more similar to the modelled SMB (Fig. 7). Considering velocities are negligible on Kongsvegen (Melvold and Hagen, 1998), the spatial variability of $\partial h / \partial t$ must be governed by SMB, most likely the distribution of snowfall, which is slightly positively biased towards the center line.

Figure 7 also presents the results of the SMB model on Kronebreen from 1969 to present. The cumulative mass balance remained slightly positive until the mid-1990s, when, similarly to Kongsvegen, the mass balance became more negative. The geodetic balance of Kronebreen shows a loss of $\sim 18-20 \mathrm{~m}$ w.e. within the time period. We suggest the strikingly large difference between the geodetic balance and $\mathrm{SMB}$ is caused by calving.

\section{Flux divergence}

Figure 7 makes it clear that on Kronebreen the residual between the geodetic balance and $\mathrm{SMB}$ is significantly negative. This component reflects the loss of ice due to calving, and is on the order of ten times the cumulative SMB. To analyze this in more detail, the average annual SMB and elevation change is plotted against elevation in Figure 8. On Kongsvegen, the difference between these curves is small and represents any systematic error related to $\partial h / \partial t$ and $b$. This error can be due, for example, to a failed prescription of $\rho_{\text {eff }}$ in $\kappa$ (Eqns (6) and (7)) or to unaccounted internal accumulation. On Kronebreen, the difference between $\partial h / \partial t$ and $b$ is greater. We propose that $\nabla \vec{q}$ is dominated by the emergence velocity below the ELA, as errors related to $\rho_{\text {eff }}$ are minimal. Above the ELA, this may represent the 


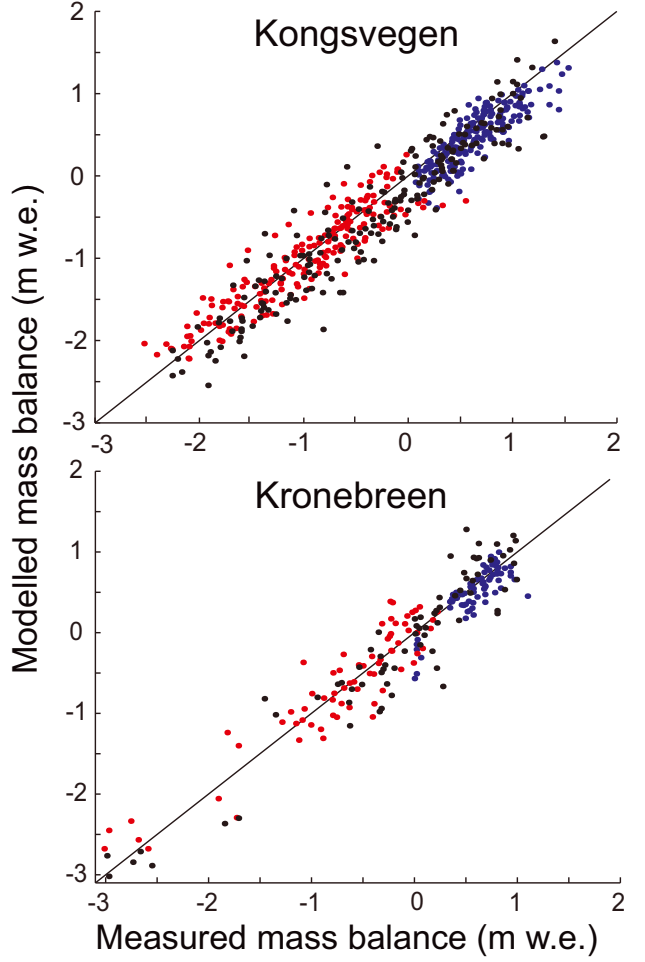

Fig. 6. The measured vs modelled winter (blue), summer (red) and net (black) stake mass balance on Kongsvegen from 1987 to 2008 and on Kronebreen from 2003 to 10. The rmse for each season is presented in Table 3.

submergence velocity, though greater uncertainty prevails due to the compressible firn area. The slope of $\nabla \vec{q}$ with elevation increases from epoch I to epoch II (Fig. 8). This is interpreted as a larger influx of ice that compensates for ice loss through the $\mathrm{SMB}$, resulting in a relatively flat $\partial \mathrm{h} / \partial t$ gradient with elevation. Above the ELA, submergence rates may be on the order of -1 to $-2 \mathrm{~m} \mathrm{a}^{-1}$, though unaccounted internal accumulation in the SMB or a lower $\kappa$ in the conversion of $\partial h / \partial t$ to water equivalent will reduce this value.

The use of the smallest glacier area as a 'reference' surface for integration of the geometric changes and mass-balance components makes a drainage basin balance assessment possible (similar to Bindschadler, 1984). The 2007 front position functions as a flux gate in all calculations. The integration of the SMB over this area in both epochs is the glacier-wide balance ( $B$ in Eqn (13)). Integration of the elevation changes over this same area results in the volume change, $\partial V / \partial t$. The difference results in an estimate of the ice flux, $Q$, through the 2007 flux gate. To account for the retreat, we also estimated the volume of ice loss over the area of retreat, $\partial V_{\mathrm{r}} / \partial t$, using the bathymetry in the retreat areas (Kehrl and others, 2011). SMB of the retreat area, $B_{\mathrm{r}}$, is estimated by applying the SMB model to the entire area of retreat, and linearly scaling the time series of $B_{\mathrm{r}}$ down to zero. This essentially assumes a linear retreat of the front.

Table 4 provides estimates of the components in Eqns (1214) for both glaciers and epochs assuming $\kappa=0.9$. On Kongsvegen, $B$ is the largest component of $\partial V / \partial t$ and the magnitude of $B$ increased threefold from epoch I to epoch II. A slight residual between $\partial V / \partial t$ and $B$ persists on Kongsvegen. Kronebreen exhibits the opposite behavior. In epoch I, $B$ is $2.5 \%$ of $\partial V / \partial t$, making the calving flux,

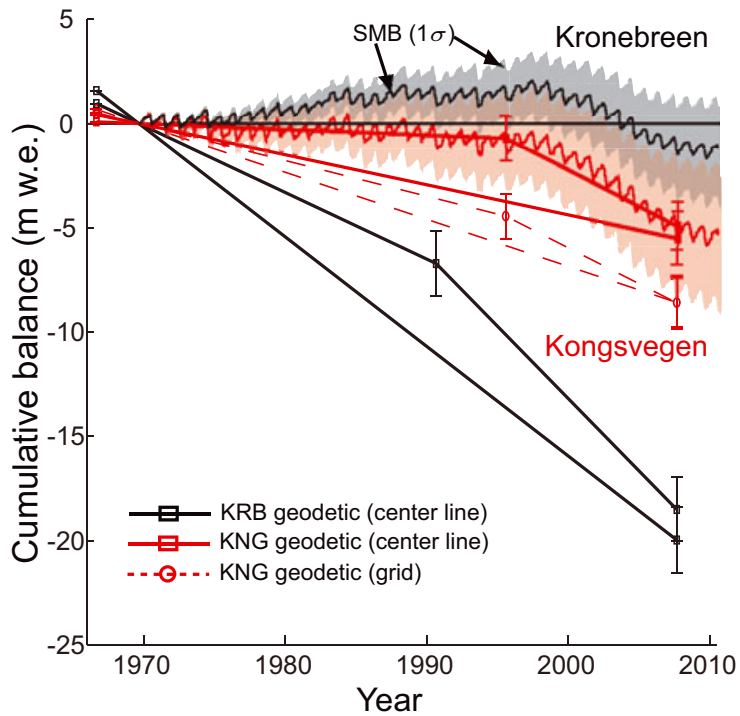

Fig. 7. The cumulative SMB model for Kongsvegen (red) and Kronebreen (black). The error zone is one standard deviation, $\sigma$, of model runs using DDFs of $\pm 0.5 \mathrm{~mm} \mathrm{~K}^{-1} \mathrm{~d}^{-1}$ around the central values provided in Table 3 . The cumulative geodetic balance is also shown at squares and circles with connecting lines. The dashed red line shows the geodetic balance estimated using the full-range $\partial h / \partial t$ field, while the straight lines show those using the center line. Kronebreen is only shown with the center-line value as there was no visible difference between the center-line and full-range $\partial h / \partial t$ field for 1966-2007. All changes are relative to 1969, when the meteorological observations were initiated.

$Q, 97.5 \%$ of ice loss during this epoch. In epoch II, $B$ doubled, comprising $25 \%$ of $\partial V / \partial t$ while $Q$ represents $75 \%$ of ice loss. Despite the decrease in the proportion of calving to volume change, the effective calving through the 2007 flux gate, $Q$, increased by 1.5 times in epoch II compared with epoch I. The difference is slightly reduced when calculating the net flux, $Q^{\prime}$, including the retreat flux, $Q_{\mathrm{r}}$, which is dependent not only on $Q$ but also on the underlying topography of the retreat area. Finally, $Q^{\prime}$ and $Q_{r}$ also include any ocean-induced melt that occurs on the vertical front of the glacier below sea level.

\section{DISCUSSION}

\section{Assumptions and errors}

The significance of errors on estimations is strongly dependent on the magnitude of the observed glacier changes. Many approaches for estimating errors in both in situ glaciologic mass balances and geodetic volume change estimates have been applied, commonly using the statistical theory of stochastic error propagation. For example, Thibert and others (2008) and Zemp and others (2010) keep very detailed track of systematic uncertainties that are combined with the stochastic error to form the total error. The stochastic errors of the estimates are relatively easy to handle, while the systematic errors are difficult to detect and quantify. In this section, first we describe the stochastic and controlled systematic errors of each of the estimated mass continuity components. Then we discuss the systematic errors related to the assumptions we have applied, including sensitivity tests on these assumptions. 


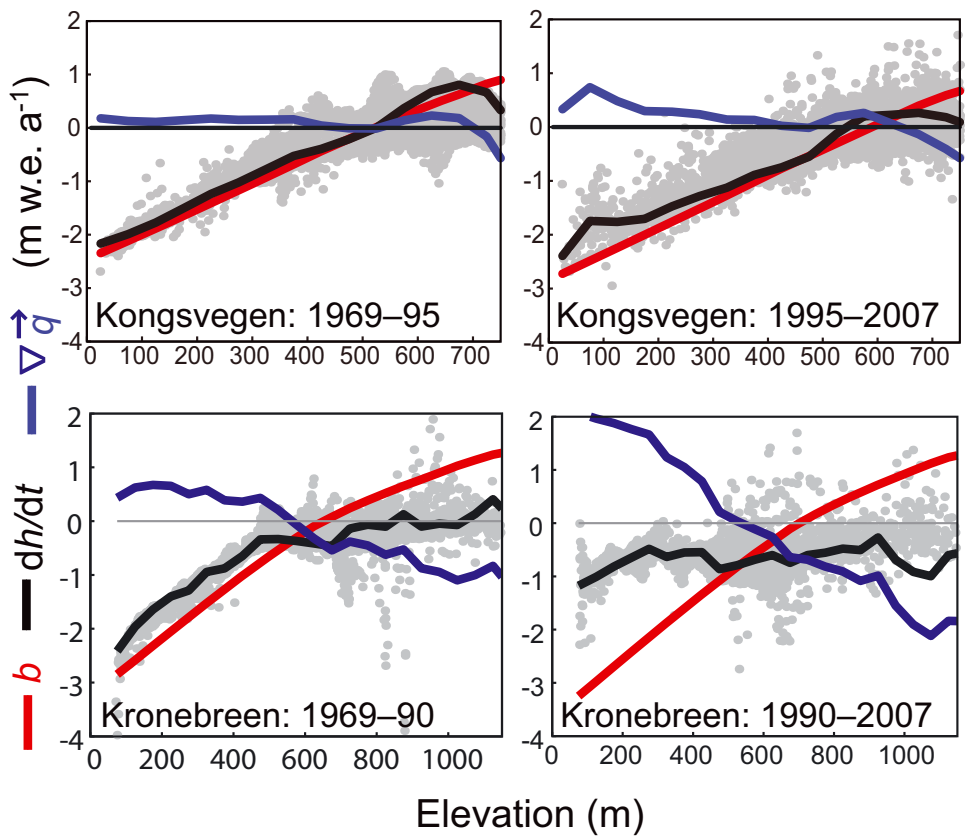

Fig. 8. The annual average surface mass-balance rates, $b$ (red), elevation change rates, $\partial h / \partial t$ (black), and the difference between them (blue) on Kongsvegen (top) and Kronebreen (bottom). Elevation change rate pixels are shown in gray. On Kongsvegen, $\nabla \vec{q}$ is essentially zero and thus the blue line represents an error term as $\partial h / \partial t$ and $b$ have been shown to be equal (Melvold and Hagen, 1998; Hagen and others, 2005). On Kronebreen, $\nabla \vec{q}$ is positive below the ELA and negative above. The slope of $\nabla \vec{q}$ with elevation increases from epoch I to epoch II.

For the geodetic estimates, the stochastic point error is estimated as the standard deviation, $\sigma$, of elevation residuals between two DEMs over stable terrain (Table 2, maximum $10 \mathrm{~m}$ ). The error about the mean elevation change is then obtained by the standard error equation, assuming an autocorrelation length of $1 \mathrm{~km}$ (Nuth and others, 2007). Systematic errors in the DEMs are controlled by first coregistering the data, and the triangulated elevation residual between three DEMs over stable terrain is an estimate of the systematic bias remaining (the lower part of Table 2, specifically 1960-1990-2007 for Kronebreen and 19661995-2007 for Kongsvegen). Systematic and stochastic errors are combined through the root sum of squares (rss), resulting in a final error dominated by the systematic component. The geodetic error is then $\sim 10-25 \%$ of the volume change (Table 4), though it can be $>100 \%$ when the change is small (Kongsvegen, epoch I).
Errors of the in situ stake measurements at an annual resolution are relatively small compared with the error introduced by spatial extrapolation (i.e. not capturing the horizontal variability). Additionally, we model SMB empirically by relating the specific seasonal winter and summer measurements to temperature and precipitation. The accuracy of this approach is strongly dependent upon the calibrated model parameters. Therefore, error of the cumulative mass-balance series is estimated by taking one standard deviation of model outputs by varying DDFs for snow and ice of $0.5 \mathrm{~mm}^{\circ} \mathrm{C}^{-1} \mathrm{a}^{-1}$ around the central value provided in Table 3. The error in $B$ is $\sim 30-200 \%$ of the Kongsvegen $\partial V / \partial t$, since changes are not strongly different from zero. On Kronebreen, error in $B$ is on the order of 10$15 \%$ of $\partial V / \partial t$ (Table 4$)$.

The error for the calving flux is then the combined rss of the $\partial V / \partial t$ and $B$ errors, and is $\sim 25 \%$ of the estimated

Table 4. The volume change, $\partial V / \partial t$, surface mass balance, $B$, and flux, $Q$, estimated for both glaciers in epochs I (1969-1990/95) and II (1990/95-2007). The components of the retreated area, $\partial V_{r} / \partial t$ and $B_{r}$, between 1966 and 1990/95 are also provided. $Q$ is the flux through the gate defined by the 2007 front position, $Q_{r}$ is the calving flux associated with the retreat area and $Q^{\prime}$ is the total calving flux including the retreat area (Eqn (14)). The area of Kongsvegen is 182, 173 and $173 \mathrm{~km}^{2}$ in 1966, 1995 and 2007, respectively. The area of Kronebreen is 392,388 and $387 \mathrm{~km}^{2}$ in 1966, 1990 and 2007, respectively. Units of all mass continuity components are $\mathrm{km}^{3}$ w.e. $\mathrm{a}^{-1}$

\begin{tabular}{|c|c|c|c|c|c|c|c|}
\hline & $\partial v / \partial t$ & $\partial V_{\mathrm{r}} / \partial t$ & $B$ & $B_{\mathrm{r}}$ & $Q$ & $Q^{\prime}$ & $Q_{\mathrm{r}}$ \\
\hline \multicolumn{8}{|l|}{ Kongsvegen } \\
\hline Epoch I & $\begin{array}{c}-0.005 \\
( \pm 0.006)\end{array}$ & $\begin{array}{c}-0.020 \\
( \pm 0.002)\end{array}$ & $\begin{array}{c}-0.023 \\
( \pm 0.010)\end{array}$ & $\begin{array}{c}-0.015 \\
( \pm 0.004)\end{array}$ & $\begin{array}{c}0.018 \\
( \pm 0.012)\end{array}$ & $\begin{array}{c}0.013 \\
( \pm 0.013)\end{array}$ & $\begin{array}{c}-0.005 \\
( \pm 0.004)\end{array}$ \\
\hline Epoch II & $\begin{array}{c}-0.061 \\
( \pm 0.016)\end{array}$ & $\begin{array}{l}- \\
-\end{array}$ & $\begin{array}{c}-0.071 \\
( \pm 0.017)\end{array}$ & $\begin{array}{l}- \\
-\end{array}$ & $\begin{array}{c}0.010 \\
( \pm 0.023)\end{array}$ & $\begin{array}{l}- \\
-\end{array}$ & $\begin{array}{l}- \\
-\end{array}$ \\
\hline \multicolumn{8}{|l|}{ Kronebreen } \\
\hline Epoch I & $\begin{array}{c}-0.125 \\
( \pm 0.025)\end{array}$ & $\begin{array}{c}-0.023 \\
( \pm 0.003)\end{array}$ & $\begin{array}{c}0.006 \\
( \pm 0.020)\end{array}$ & $\begin{array}{c}-0.012 \\
( \pm 0.003)\end{array}$ & $\begin{array}{c}-0.130 \\
( \pm 0.031)\end{array}$ & $\begin{array}{c}-0.141 \\
( \pm 0.031)\end{array}$ & $\begin{array}{c}-0.011 \\
( \pm 0.004)\end{array}$ \\
\hline Epoch II & $\begin{array}{c}-0.267 \\
( \pm 0.034)\end{array}$ & $\begin{array}{l}- \\
-\end{array}$ & $\begin{array}{c}-0.069 \\
( \pm 0.029)\end{array}$ & $\begin{array}{l}- \\
-\end{array}$ & $\begin{array}{c}-0.198 \\
( \pm 0.045)\end{array}$ & $\begin{array}{l}- \\
-\end{array}$ & $\begin{array}{l}- \\
-\end{array}$ \\
\hline
\end{tabular}


Table 5. Sensitivity tests applied on the mass continuity solution of $Q$ where $\Delta Q=Q_{\text {ref }}-Q_{\text {scenario }}$. The reference assumes $\kappa=0.9$ over the entire glacier. Scenario 1 assumes $\kappa=0.55$ above the ELA. Scenario 2 assumes that $50 \%$ of melt above the ELA is maintained in the system. For these sensitivity tests, the ELA is held constant at 500 and $700 \mathrm{~m}$ a.s.l. for Kongsvegen and Kronebreen, respectively. All units are $\mathrm{km}^{3}$ w.e. $\mathrm{a}^{-1}$

\begin{tabular}{|c|c|c|c|c|c|c|c|c|}
\hline & \multicolumn{4}{|c|}{ Kongsvegen } & \multicolumn{4}{|c|}{ Kronebreen } \\
\hline & $\partial V / \partial t$ & $B$ & $Q$ & $\Delta Q$ & $\partial V / \partial t$ & $B$ & $Q$ & $\Delta Q$ \\
\hline Period I - reference & -0.005 & -0.023 & 0.018 & - & -0.125 & 0.006 & -0.131 & - \\
\hline Scenario 1 & -0.023 & -0.023 & 0.000 & 0.018 & -0.123 & 0.006 & -0.129 & -0.002 \\
\hline Scenario 2 & -0.005 & 0.007 & -0.012 & 0.030 & -0.125 & 0.030 & -0.155 & 0.024 \\
\hline Scenario $1+2$ & -0.023 & 0.007 & -0.030 & 0.048 & -0.123 & 0.030 & -0.153 & 0.022 \\
\hline Period II - reference & -0.061 & -0.071 & 0.010 & - & -0.267 & -0.069 & -0.198 & - \\
\hline Scenario 1 & -0.066 & -0.071 & 0.005 & 0.005 & -0.224 & -0.069 & -0.155 & -0.043 \\
\hline Scenario 2 & -0.061 & -0.031 & -0.030 & 0.040 & -0.267 & -0.028 & -0.239 & 0.041 \\
\hline Scenario $1+2$ & -0.066 & -0.031 & -0.035 & 0.045 & -0.224 & -0.028 & -0.196 & -0.002 \\
\hline
\end{tabular}

calving flux on Kronebreen (Table 4). On Kongsvegen, we do not expect much ice loss through calving, so any residual between $\partial V / \partial t$ and $B$ is associated with some unremoved systematic biases. Some ice could be lost through entrainment into Kronebreen at the tongue, though the sign of $Q$ would be negative rather than positive. Interestingly, the magnitude of the bias is of the same order of magnitude as the estimated decadal average accumulation of superimposed ice (Brandt and others, 2008), an effect that would cause a positive value in the difference between $\partial \mathrm{V} / \partial t$ and $B$.

The weakest part of our application of the mass continuity equation is the potential bias induced by our simplifying assumptions. The density ratio, $\kappa$, required to convert elevation changes into water-equivalent volume changes is not completely certain and commonly assumes a constant value equal to the density of ice. This assumption is satisfied in the ablation area, but is questionable in the compressible firn pack. In the firn area, the density of ice can be assumed, based upon Sorge's law, which states that the density at a given depth does not change with time, provided there is a constant accumulation rate (Bader, 1954). However, a change in the firn-pack thickness and/or density will invalidate Sorge's law. We also assume that englacial and basal mass-balance components are negligible, but these components are probably orders of magnitude smaller than the surface component (Cuffey and Paterson, 2010). Finally, mass-balance measurements, $b$, made in the accumulation area assume that all melt discharges from the glacier, although internal accumulation may be occurring. To assess the sensitivity of these assumptions on $Q$, we apply two scenarios, the first related to $\partial h / \partial t$ in the definition of $\kappa$ and the second related to $b$. The scenarios are based upon varying these terms above the average ELA, defined at 500 and $700 \mathrm{~m}$ a.s.I. for Kongsvegen and Kronebreen, respectively.

Scenario 1: Test of firn-thickness changes. Use $\kappa=0.55$ for $\partial h / \partial t$ above the ELA.

Scenario 2: Test of internal accumulation. Assume that $50 \%$ of the modelled mass losses, $b$, above the ELA are maintained in the system.

These scenarios provide upper and lower bounds to the derived flux through a fixed gate, $Q$, based upon simplified assumptions of systematic bias (Table 5). The effect of scenario 1 is opposite on the two glaciers because Kongsvegen is thickening above the ELA whereas Kronebreen is thinning above the ELA. Scenario 2 obviously increases the
SMB. Cases of firn compaction would theoretically reduce $\kappa$ with limits approaching zero if the entire $\partial h / \partial t$ is the result of firn compaction. However, this is rather unlikely, mainly because the positive and negative observed $\partial h / \partial t$ above the ELA on Kongsvegen and Kronebreen, respectively, would imply that the firn pack of these adjacent glaciers is expanding and compressing, respectively, despite the similar climatic situations. In addition, no changes in the firn thickness of the upper basin of Kronebreen were observed between 1992 and 2005 (Uchida and others, 1993; Sjögren and others, 2007; Nuth and others, 2010). In summary, the worst-case scenario of these simplifying assumptions results in a $20 \%$ difference in estimates of $Q$ for Kronebreen. On Kongsvegen, the effects are slightly larger, due to the smaller magnitude of $\partial V / \partial t$; however, the good coherence between $\partial V / \partial t$ and $B$ through Eqn (11) (Fig. 7) suggests a proper assumption of $\kappa$.

\section{Interpretation}

The comparison between SMB and geometric changes is based upon mass continuity. We also utilize concepts derived by Elsberg and others (2001) about the difference between the 'conventional' mass balance, which is the actual mass change, and the 'reference' mass balance, which is integration over a constant geometry. In their study, the reference surface is held constant at the largest area, and positive corrections are applied, based upon the geodetic volume changes, since the glacier is thinning and retreating. In our study, the 'reference' mass balance is obtained through integration over the newest (i.e. smallest) area, and transformation to conventional mass balances is in the negative direction to account for frontal retreat, $B_{\mathrm{r}}$. The use of the smallest area additionally allows for full balance assessment (as in Bindschadler, 1984) of the glacier basin, by using the most recent front position as a flux gate.

Kongsvegen provides control on the SMB model because it is in its quiescent phase of a surge cycle (Melvold and Hagen, 1998; Hagen and others, 2005). However, Figure 5f shows the center-line elevation change rates on Kongsvegen are not perfectly representative of the entire surface of Kongsvegen. Figure 7 shows the cumulative geodetic balances computed by the 'grid' approach and by the 'hypsometric' approach using the center line. The cumulative surface mass balance matches closest to the center-line geodetic estimates. The lack of significant ice flow suggests that the spatial $\partial h / \partial t$ variability, which is most dominant above the ELA, is 
governed by SMB variability. This may be due to radiation variability, which can affect melt (Arnold and others, 2006), previously hypothesized to cause geodetic balances to be more negative than either traditionally measured mass balances or center-line extrapolated estimates on a nearby small valley glacier, Midtre Lovénbreen (Rees and Arnold, 2007; Barrand and others, 2010). If this were so, then we could expect that the reduced radiation along the edges of the glacier due to topographic shading (Arnold and others, 2006) would reduce melt and thus a center-line estimate would be more negative than a glacier-wide estimate. The opposite is seen here, and in previous studies.

We suggest instead that lateral accumulation variability is responsible for the underestimation of the modelled $\mathrm{SMB}$ and center-line geodetic balance (Fig. 7). Centerline $\partial h / \partial t$ above $500 \mathrm{~m}$ on Kongsvegen is more positive than the elevation bin average (Fig. 5), and slightly larger accumulation is measured along the main center line than in the two northern basins measured within the past 10 years (J. Kohler, unpublished data). Accumulation affects the timing of albedo decrease within the summer mass-balance season and the DDF transition from snow to ice within the model. This results in the model underestimating melt in areas where snow accumulation is overestimated. Therefore, the combined effect of an overestimated accumulation and an underestimated melt results in an underestimated cumulative SMB (and center-line geodetic balance) as compared to the full spatially integrated geodetic balance (Fig. 7).

The SMB of Kongsvegen has decreased drastically during epoch II (Table 4), especially since the late 1990s-early 2000s (Fig. 7). On Kronebreen, a similar decrease in the $\mathrm{SMB}$ is modelled, though this is not as great because of the higher elevation range of the Kronebreen basin. Similar rapid (geodetic) mass-balance decreases have been observed on two small land-terminating glaciers in western and central Spitsbergen (Kohler and others, 2007). Since 2007, it seems that the cumulative SMB has become less negative on both glaciers, similar to other measurements of surface mass balance and elevation changes in Svalbard (Moholdt and others, 2010a,b).

On Kronebreen, $\partial V / \partial t$ estimated from the center-line $\partial h / \partial t$ and full spatially integrated $\partial h / \partial t$ are similar within the errors. As $\partial V / \partial t$ is much larger than $B$, the flux of ice through the 2007 flux gate, $Q$, is the main contributor to $\partial V / \partial t$ over the past four decades. Interestingly, despite the increased proportion of $B$ to $\partial V / \partial t$ from epoch I to epoch II (2.5\% to $25 \%), Q$ has nearly doubled (Table 4$)$. Including the calving retreat flux, $Q_{r}$, in the estimate for the total calving flux, $Q^{\prime}$, slightly reduces the difference. However, $Q_{r}$, and therefore $Q^{\prime}$, is dependent upon both the influx of ice upstream, $Q$, and the underlying topography. For example, Vieli and others (2001) model a rapid retreat over a basal depression and suggest that the rapid retreat is more dominantly an effect of bed topography rather than changes in climate. Therefore, it may be more feasible in this study to compare values for $Q$ out of a fixed flux gate. It remains unclear how the retreat flux, $Q_{r}$, affects $Q$ during the retreat of epoch I.

We can only speculate on reasons for the calving flux increase, as in situ measurements of velocity covering the entire period are not available. Available measurements do show interannual variability (Kääb and others, 2005), although no drastic increases have been detected over the past four decades (Voigt, 1966; Lefauconnier and others, 1994b; Kääb and others, 2005). The flux of ice comprises both deformation and sliding components. Deformation velocity reacts slowly, due to its dependence upon ice thickness and slope. Conversely, glacier sliding reacts faster in relation to the subglacial drainage conditions (Iken and Bindschadler, 1986; Kamb, 1987). Recently, accelerated glacier motion has been observed to be related to water pulses that exceed the drainage system capacity (Bartholomaus and others, 2008). Schoof (2010) suggests that increased sliding velocities are due to more frequent water pulses, rather than an increase in the melt volume. Our calving estimates are averages over decades and may be indirectly related to the temporal average decrease in $B$. Since Kronebreen is losing volume over the entire glacier basin, especially in epoch II, ice deformation is supposedly decreasing. Therefore, it can be suggested that the increase in calving flux is related to the sliding velocity, and possibly an increase in the decadal average frequency and magnitude of water pulses.

\section{CONCLUSIONS}

In this study, we apply mass continuity to solve for the calving flux of a marine-terminating glacier, Kronebreen, from measured elevation changes and modelled surface mass-balance changes. Elevation changes are derived for two epochs, 1966-1990/95 and 1990/95-2007. The SMB is modelled using a degree-day approach for melt and a regression scheme for precipitation, both calibrated against observations. The negligible calving- and quiescent-phase behavior of neighboring Kongsvegen provides additional control on the SMB model. To practically apply mass continuity, we define our 'reference' surface (Elsberg and others, 2001) as the 2007 (smallest) area which declares this front position as a flux gate.

In the case of Kongsvegen over the 1966-2007 period, the geodetic balance calculated using the full spatial coverage of $\partial h / \partial t$ is $3 \mathrm{~m}$ more negative than the modelled cumulative SMB and the center-line estimated geodetic balance (Fig. 7). We suggest that this is a result of lateral accumulation variability, especially above the ELA, which is not accounted for by the center-line stake measurements. Such variability would cause a reduction in the albedo (and DDF) earlier in the summer season, producing more melt. This combined with a lower accumulation results in a lower SMB. Using the center-line estimates of volume change, we find small residuals between $\partial V / \partial t$ and $B$, which are not significantly different from zero, possibly reflecting unremoved systematic bias.

On Kronebreen, lateral variability in accumulation is minimal, as shown by the elevation changes (Fig. 5g). The large and systematic difference between the volume change and the SMB (Fig. 7; Table 4) represents the loss of ice through calving. When analyzed locally, the difference represents an estimate of the long-term average emergence velocities (Fig. 8), given that our definition of the effective density is correct and internal accumulation is negligible. From mass continuity, we estimate the long-term average calving flux to be $-0.14 \pm 0.03$ and $-0.20 \pm 0.05 \mathrm{~km}^{3} \mathrm{a}^{-1}\left(Q^{\prime}\right.$ and $Q$, respectively, in Table 4) for epochs I and II, respectively.

The SMB of both glaciers remained close to zero until the late 1990s, when it became increasingly negative. Since 2007, the mass balance has stabilized. On Kongsvegen, the annual average glacier-wide SMB (center line) doubled 
from $-0.21 \pm 0.08 \mathrm{ma}^{-1}$ in epoch I to $-0.41 \pm 0.10 \mathrm{ma}^{-1}$ (derived using the volumetric surface mass balance, $B+B_{\mathrm{r}}$, in Table 4 divided by the average area within the epoch; in epoch II the area did not change and therefore $B_{\mathrm{r}}=0$ ) for epoch II. On Kronebreen, the annual average glacier-wide $\mathrm{SMB}$ is more negative from $-0.02 \pm 0.06 \mathrm{~m} \mathrm{a}^{-1}$ for epoch I to $-0.18 \pm 0.03 \mathrm{~m} \mathrm{a}^{-1}$ for epoch II. On Kronebreen, the calving flux represented $97.5 \%$ and $75 \%$ of the geodetic volume change in epochs I and II, respectively. Despite the decrease in the proportion of calving loss to volume loss, the average calving flux increased in epoch II. We speculate that the increase in flux is a result of a change in basal hydrological conditions, possibly indirectly related to the rapid decrease of the surface mass balance during epoch II, which could lead to more frequent and intense melt pulses that would increase velocities and calving rates (Schoof, 2010).

In summary, geodetic elevation changes have been independently compared with a modelled SMB of a landterminating glacier and a marine-terminating glacier. On calving glaciers, the residual may be large enough to allow significant estimation of the long-term calving flux, reducing the need for expensive velocity and ice-thickness measurements. Nonetheless, comparison of this approach in cases where continuous long-term velocity measurements of the calving glacier tongue are available will provide insightful validation. Furthermore, future applications of surface massbalance models simulated with regional climate models may soon allow larger spatial extrapolation, which can be combined with the more readily available geodetic volume change estimates by DEM differencing to better define the proportion of ice loss to calving.

\section{ACKNOWLEDGEMENTS}

This work was funded through the Norwegian Research Council (NFR), IPY-GLACIODYN project (176076). We acknowledge the ice2sea project, funded by the European Commission's 7th Framework Programme through grant No. 226375, ice2sea manuscript No. 025. This work is a contribution to the ESA Climate Change Initiative Project 'Glaciers_cci' (4000101778/10/l-AM). Fieldwork from 2007 to 2010 was partially funded by the Arctic Stipend provided by the Svalbard Science Forum. We thank G. Moholdt, M. Engelhardt and T. Østby for proofing early versions of the manuscript. We thank the Norwegian Polar Institute mapping department for providing the early DEMs. The SPOT5-HRS DEM (ID: GES07-043-NorthWestSvalbard) was obtained through the IPY-SPIRIT program (Korona and others, 2009) (C)CNES 2008 and SPOT Image 10 2008, all rights reserved. Thanks to G. Hamilton and D. Benn for their constructive criticisms as a part of reviewing a PhD dissertation. We thank T.H. Jacka, I. Willis and an anonymous reviewer for their comments and suggestions, which significantly improved an earlier version of this paper.

\section{REFERENCES}

Abdalati W and 9 others (2004) Elevation changes of ice caps in the Canadian Arctic Archipelago. J. Geophys. Res., 109(F4), F04007 (doi: 10.1029/2003JF000045)

Ahn Y and Box JE (2010) Glacier velocities from time-lapse photos: technique development and first results from the Extreme Ice Survey (EIS) in Greenland. J. Glaciol., 56(198), 723-734
Altena B (2008. Hypsometric measurements in Holtedahlfonna in 1966 and 1990. (Report Bachelor Internship, Hogeschool Utrecht)

Andreassen LM (1999) Comparing traditional mass balance measurements with long-term volume change extracted from topographical maps: a case study of Storbreen glacier in Jotunheimen, Norway, for the period 1940-1997. Geogr. Ann., 81A(4), 467-476

Arendt AA, Echelmeyer KA, Harrison WD, Lingle CS and Valentine VB (2002) Rapid wastage of Alaska glaciers and their contribution to rising sea level. Science, 297(5580), 382-386

Arnold NS, Rees WG, Hodson AJ and Kohler J (2006) Topographic controls on the surface energy balance of a high Arctic valley glacier. J. Geophys. Res., 111(F2), F02011 (doi: 10.1029/2005JF000426)

Bader H (1954) Sorge's Law of densification of snow on high polar glaciers. J. Glaciol., 2(15), 319-323

Barrand NE, James TD and Murray T (2010) Spatio-temporal variability in elevation changes of two high-Arctic valley glaciers. J. Glaciol., 56(199), 771-780

Bartholomaus TC, Anderson RS and Anderson SP (2008) Response of glacier basal motion to transient water storage. Nature Geosci., 1(1), 33-37

Baumberger A (2008) Massebalanse på Kronebreen/Holtedahlfonna, Svalbard - kontrollerende faktorer. (Master's thesis, University of Oslo)

Berthier E, Arnaud Y, Baratoux D, Vincent C and Rémy F (2004) Recent rapid thinning of the Mer de Glace glacier derived from satellite optical images. Geophys. Res. Lett., 31(17), L17401 (doi: 10.1029/2004GL020706)

Berthier E, Schiefer E, Clarke GKC, Menounos B and Rémy F (2010) Contribution of Alaskan glaciers to sea-level rise derived from satellite imagery. Nature Geosci., 3(2), 92-95

Bindschadler RA (1984) Jacobshavns Glacier drainage basin: a balance assessment. J. Geophys. Res., 89(C2), 2066-2072

Bouillon A, Bernard M, Gigord P, Orsoni A, Rudowski V and Baudoin A (2006) SPOT 5 HRS geometric performances: using block adjustment as a key issue to improve quality of DEM generation. ISPRS J. Photogramm. Rem. Sens., 60(3), 134-146

Braithwaite RJ (1981) On glacier energy balance, ablation, and air temperature. J. Glaciol., 27(97), 381-391

Braithwaite RJ (1995) Positive degree-day factors for ablation on the Greenland ice sheet studied by energy-balance modelling. J. Glaciol., 41(137), 153-160

Brandt O, Kohler J and Lüthje M (2008) Spatial mapping of multiyear superimposed ice on the glacier Kongsvegen, Svalbard. J. Glaciol., 54(184), 73-80

Burgess DO, Sharp MJ, Mair DWF, Dowdeswell JA and Benham TJ (2005) Flow dynamics and iceberg calving rates of Devon Ice Cap, Nuvavut, Canada. J. Glaciol., 51(173), 219-230

Cox LH and March RS (2004) Comparison of geodetic and glaciological mass-balance techniques, Gulkana Glacier, Alaska, USA. J. Glaciol., 50(170), 363-370

Cuffey KM and Paterson WSB (2010) The physics of glaciers, 4th edition. Butterworth-Heinemann, Oxford

Elsberg DH, Harrison WD, Echelmeyer KA and Krimmel RM (2001) Quantifying the effects of climate and surface change on glacier mass balance. J. Glaciol., 47(159), 649-658

Gudmundsson GH and Bauder A (1999) Towards an indirect determination of the mass-balance distribution of glaciers using the kinematic boundary condition. Geogr. Ann., 81A(4), 575-583

Hagen JO, Melvold K, Eiken T, Isaksson E and Lefauconnier B (1999) Mass balance methods on Kongsvegen, Svalbard. Geogr. Ann., 81A (4), 593-601

Hagen JO, Eiken T, Kohler J and Melvold K (2005) Geometry changes on Svalbard glaciers: mass-balance or dynamic response? Ann. Glaciol., 42, 255-261 
Hock R (2003) Temperature index melt modelling in mountain areas. J. Hydrol., 282(1-4), 104-115

Hubbard A and 6 others (2000) Glacier mass-balance determination by remote sensing and high-resolution modelling. J. Glaciol., 46(154), 491-498

Huss M, Bauder A and Funk M (2009) Homogenization of long-term mass-balance time series. Ann. Glaciol., 50(50), 198-206

Iken A and Bindschadler RA (1986) Combined measurements of subglacial water pressure and surface velocity of Findelengletscher, Switzerland: conclusions about drainage system and sliding mechanism. J. Glaciol., 32(110), 101-119

Kääb A (2000) Photogrammetric reconstruction of glacier mass balance using a kinematic ice-flow model: a 20 year time series on Grubengletscher, Swiss Alps. Ann. Glaciol., 31, 45-52

Kääb A and Funk M (1999) Modelling mass balance using photogrammetric and geophysical data: a pilot study at Griesgletscher, Swiss Alps. J. Glaciol., 45(151), 575-583

Kääb A, Lefauconnier B and Melvold K (2005) Flow field of Kronebreen, Svalbard, using repeated Landsat 7 and ASTER data. Ann. Glaciol., 42, 7-13

Kamb B (1987) Glacier surge mechanism based on linked cavity configuration of the basal water conduit system. J. Geophys. Res., 92(B9), 9083-9100

Kehrl LM, Hawley RL, Powell RD and Brigham-Grette J (2011) Glacimarine sedimentation processes at Kronebreen and Kongsvegen, Svalbard, J. Glaciol., 57 (205), 841-847

Kohler J. and 7 others (2007) Acceleration in thinning rate on western Svalbard glaciers. Geophys. Res. Lett., 34(18), L18502 (doi: 10.1029/2007GL030681)

König M, Wadham J, Winther JG, Kohler J and Nuttall A-M (2002) Detection of superimposed ice on the glaciers Kongsvegen and midre Lovénbreen, Svalbard, using SAR satellite imagery. Ann. Glaciol., 34, 335-342

Korona J, Berthier E, Bernard M, Rémy F and Thouvenot E (2009) SPIRIT. SPOT 5 stereoscopic survey of Polar Ice: reference images and topographies during the fourth International Polar Year (2007-2009). ISPRS J. Photogramm. Rem. Sens, 64(2), 204-212

Krimmel RM (1999) Analysis of difference between direct and geodetic mass balance measurements at South Cascade Glacier, Washington. Geogr. Ann., 81A(4), 653-658

Langley $\mathrm{K}$ and 6 others (2007) Use of C-band ground penetrating radar to determine backscatter sources within glaciers. IEEE Trans. Geosci. Remote Sens., 45(5), 1236-1246

Lefauconnier B and Hagen JO (1990) Glaciers and climate in Svalbard: statistical analysis and reconstruction of the Brøggerbreen mass balance for the last 77 years. Ann. Glaciol., 14, 148-152

Lefauconnier B, Hagen JO and Rudant JP (1994a) Flow speed and calving rate of Kongsbreen glacier, Svalbard, using SPOT images. Polar Res., 13(1), 59-65

Lefauconnier B, Hagen JO, Pinglot JF and Pourchet M (1994b) Mass-balance estimates on the glacier complex Kongsvegen and Sveabreen, Spitsbergen, Svalbard, using radioactive layers. J. Glaciol., 40(135), 368-376

Lefauconnier B, Hagen JO, Orbaek JB, Melvold K and Isaksson E (1999) Glacier balance trends in the Kongsfjorden area, western Spitsbergen, Svalbard, in relation to the climate. Polar Res., $\mathbf{1 8}(2)$, 307-313

Liestøl O (1988) The glaciers in the Kongsfjorden area, Spitsbergen. Nor. Geogr. Tidsskr., 42(4), 231-238

Luthcke SB, Arendt AA, Rowlands DD, McCarthy JJ and Larsen CF (2008) Recent glacier mass changes in the Gulf of Alaska region from GRACE mascon solutions. J. Glaciol., 54(188), 767-777

Melvold K and Hagen JO (1998) Evolution of a surge-type glacier in its quiescent phase: Kongsvegen, Spitsbergen, 1964-95. J. Glaciol., 44(147), 394-404

Moholdt G, Hagen JO, Eiken T and Schuler TV (2010a) Geometric changes and mass balance of the Austfonna ice cap, Svalbard. Cryosphere, 4(1), 21-34
Moholdt G, Nuth C, Hagen JO and Kohler J (2010b) Recent elevation changes of Svalbard glaciers derived from ICESat laser altimetry. Remote Sens. Environ., 114(11), 2756-2767

Nuth C and Kääb A (2011) Co-registration and bias corrections of satellite elevation data sets for quantifying glacier thickness change, Cryosphere, 5(1), 271-290

Nuth C, Kohler J, Aas HF, Brandt O and Hagen JO (2007) Glacier geometry and elevation changes on Svalbard (1936-90): a baseline dataset. Ann. Glaciol., 46, 106-116

Nuth C, Moholdt G, Kohler J, Hagen JO and Kääb A (2010) Svalbard glacier elevation changes and contribution to sea level rise. J. Geophys. Res., 115(F1), F01008 (doi: 10.1029/2008JF001223)

Ohmura A (2001) Physical basis for the temperature-based meltindex method. J. Appl. Meteorol., 40(4), 753-761

Østrem G and Brugman M (1991) Glacier mass-balance measurements. A manual for field and office work. National Hydrology Research Institute, Environment Canada, Saskatoon, Sask. (NHRI Science Report 4)

Paul F (2010) The influence of changes in glacier extent and surface elevation on modeled mass balance. Cryos. Discuss., 4(2), 737-766

Rees WG and Arnold NS (2007) Mass balance and dynamics of a valley glacier measured by high-resolution LiDAR. Polar Rec., 43(4), 311-319

Schoof C (2010) Ice-sheet acceleration driven by melt supply variability. Nature, 468(7325), 803-806

Schuler TV, Loe E, Taurisano A, Eiken T, Hagen JO and Kohler J (2007) Calibrating a surface mass-balance model for Austfonna ice cap, Svalbard. Ann. Glaciol., 46, 241-248

Sicart JE, Hock R and Six D (2008) Glacier melt, air temperature, and energy balance in different climates: the Bolivian Tropics, the French Alps, and northern Sweden. J. Geophys. Res., 113(D24), D24113 (doi: 10.1029/2008JD010406)

Sjögren B and 6 others (2007) Determination of firn density in ice cores using image analysis. J. Glaciol., 53(182), 413-419

Taurisano A. and 6 others (2007) The distribution of snow accumulation across Austfonna ice cap Svalbard: direct measurements and modelling. Polar Res., 26(1), 7-13

Thibert E, Blanc R, Vincent C and Eckert N (2008) Glaciological and volumetric mass-balance measurements: error analysis over 51 years for Glacier de Sarennes, French Alps. J. Glaciol., 54(186), 522-532

Uchida T. and 7 others (1996) Ice core analyses and borehole temperature measurements at the drilling site on Åsgårdfonna, Spitsbergen, in 1993. Mem. Natl Inst. Polar Res., 51, Special Issue, 377-386

US Army Corps of Engineers (1956) Snow hydrology: summary report of the snow investigations. North Pacific Division, US Army Corps of Engineers, Portland, OR

Van den Broeke M, Bus C, Ettema J and Smeets P (2010) Temperature thresholds for degree-day modelling of Greenland ice sheet melt rates. Geophys. Res. Lett., 37(18), L18501 (doi: 10.1029/2010GL044123)

Vieli A, Funk $\mathrm{M}$ and Blatter $\mathrm{H}$ (2001) Flow dynamics of tidewater glaciers: a numerical modelling approach. J. Glaciol., 47(159), 595-606

Voigt $U$ (1966) The determination of the direction of movement on glacier surfaces by terrestrial photogrammetry. J. Glaciol., 6(45), 359-367.

Wahr J, Swensen S, Zlotnicki V and Velicogna I (2004) Time-variable gravity from GRACE: first results. Geophys. Res. Lett., 31(11), L11501 (doi: 10.1029/2004GL019779)

Zemp M and 6 others (2010) Reanalysis of multi-temporal aerial images of Storglaciären, Sweden (1959-99). Part 2: Comparison of glaciological and volumetric mass balances. Cryosphere, 4(3), 345-357

Zwally HJ and 7 others (2005) Mass changes of the Greenland and Antarctic ice sheets and shelves and contributions to sea-level rise: 1992-2002. J. Glaciol., 51(175), 509-527 


\section{APPENDIX}
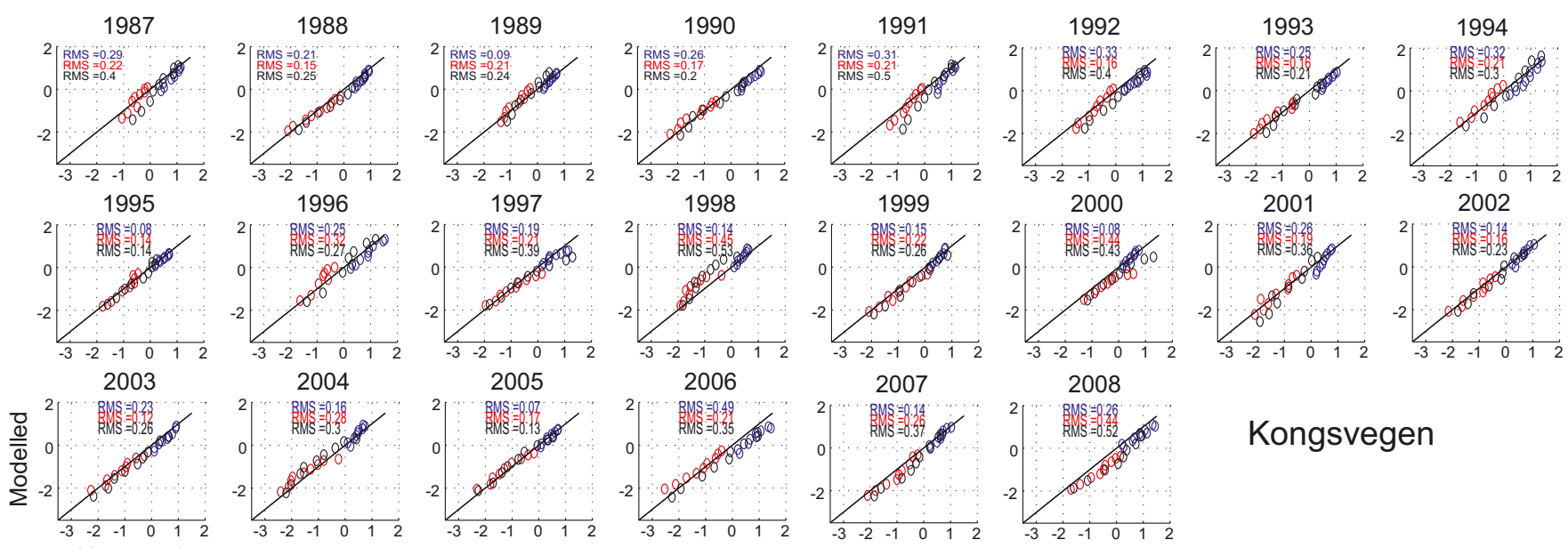

Kongsvegen Measured
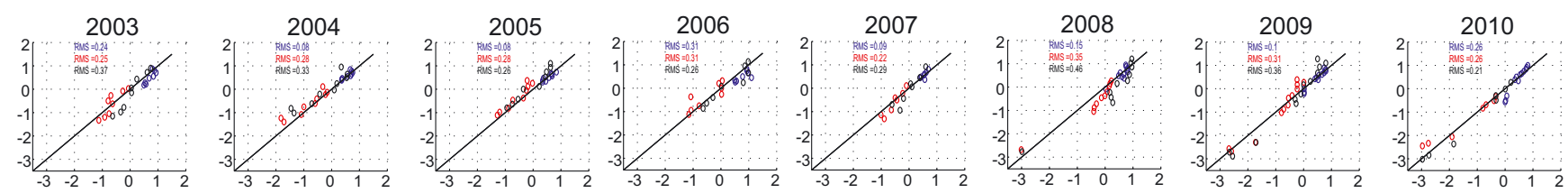

Kronebreen

Fig. 9. The measured vs modelled winter (blue), summer (red) and net (black) SMB (m w.e.) for each year, on each glacier. The colored rms values are shown with average annual values between 0.1 and $0.5 \mathrm{~m}$ w.e.

MS received 2 March 2011 and accepted in revised form 5 September 2011 